\title{
Response of the Equatorial Pacific Seasonal Cycle to Orbital Forcing
}

\author{
MichaEl P. ERB \\ Department of Environmental Sciences, Rutgers, The State University of New Jersey, New Brunswick, \\ New Jersey, and Institute for Geophysics, University of Texas at Austin, Austin, Texas \\ ANTHONY J. BROCCOLI \\ Department of Environmental Sciences, and Institute for Earth, Ocean, and Atmospheric Sciences, Rutgers, The State \\ University of New Jersey, New Brunswick, New Jersey \\ NEAL T. GRAHAM \\ Department of Environmental Sciences, Rutgers, The State University of New Jersey, New Brunswick, New Jersey \\ AMY C. ClEMENT \\ Rosenstiel School of Marine and Atmospheric Science, University of Miami, Miami, Florida \\ ANDREW T. WitTEnberg AND GABRIEL A. VeCCHI \\ Geophysical Fluid Dynamics Laboratory, and Princeton University, Princeton, New Jersey
}

(Manuscript received 1 April 2015, in final form 24 July 2015)

\begin{abstract}
The response of the equatorial Pacific Ocean's seasonal cycle to orbital forcing is explored using idealized simulations with a coupled atmosphere-ocean GCM in which eccentricity, obliquity, and the longitude of perihelion are altered while other boundary conditions are maintained at preindustrial levels. The importance of ocean dynamics in the climate response is investigated using additional simulations with a slab ocean version of the model. Precession is found to substantially influence the equatorial Pacific seasonal cycle through both thermodynamic and dynamic mechanisms, while changes in obliquity have only a small effect. In the precession experiments, western equatorial Pacific SSTs respond in a direct thermodynamic manner to changes in insolation, while the eastern equatorial Pacific is first affected by the propagation of thermocline temperature anomalies from the west. These thermocline signals result from zonal wind anomalies associated with changes in the strength of subtropical anticyclones and shifts in the regions of convection in the western equatorial Pacific. The redistribution of heat from these thermocline signals, aided by the direct thermodynamic effect of insolation anomalies, results in large changes to the strength and timing of the eastern equatorial Pacific seasonal cycle. A comparison of 10 CMIP5 mid-Holocene experiments, in which the primary forcing is due to precession, shows that this response is relatively robust across models. Because equatorial Pacific SST anomalies have local climate impacts as well as nonlocal impacts through teleconnections, these results may be important to understanding paleoclimate variations both inside and outside of the tropical Pacific.
\end{abstract}

\section{Introduction}

The equatorial Pacific Ocean has been widely studied because of its importance to global climate. Part of this importance can be attributed to El Niño-Southern

Corresponding author address: Michael P. Erb, University of Texas at Austin, 10100 Burnet Rd. (R2200), Bldg. 196, Austin, TX 78758.

E-mail: merb@ig.utexas.edu
Oscillation (ENSO), a coupled atmosphere-ocean interaction that has teleconnections to nonlocal temperature and precipitation patterns, tropical cyclone formation, and atmospheric circulation in distant regions of the globe (Diaz et al. 2001; Vecchi and Wittenberg 2010; Collins et al. 2010). However, climate can also be affected by changes in the long-term mean seasonal temperature cycle, and this annual cycle is important to aspects of the ENSO phenomenon (e.g., 
Tziperman et al. 1994, 1997; Vecchi 2006; Lengaigne and Vecchi 2010). Previous research suggests that the equatorial Pacific mean seasonal temperature cycle has changed in the past, likely having an effect on ENSO (Luan et al. 2012; Braconnot et al. 2012; Karamperidou et al. 2015) as well as local and nonlocal climate.

The present-day eastern equatorial Pacific sea surface temperature (SST) cycle is characterized by maximum warmth in boreal spring and minimum warmth in boreal summer and autumn. Farther west, near the date line, the seasonal cycle is weaker, with the warm peak occurring a month or two later in the year. West of $160^{\circ} \mathrm{E}$ there is a semiannual cycle, with warm peaks in AprilMay and in November. Because tropical insolation forcing is semiannual, with maxima near the two equinoxes, the eastern equatorial Pacific SST cycle cannot be fully explained as a direct thermodynamic response to insolation. Instead, early work highlighted the importance of winds and ocean-atmosphere coupling to the seasonal cycle of the eastern equatorial Pacific (Chang 1994, 1996; Li and Philander 1996). In particular, the positioning of the ITCZ north of the equator results in strong cross-equatorial trades during boreal summer and fall, cooling the SSTs through increased upwelling, evaporation, and potentially increased stratus clouds. These studies used sensitivity simulations to explore the role of surface heat fluxes, winds, dynamic feedbacks, and coastline orientation in determining the equatorial seasonal cycle. However, the relative importance of these elements is still a matter of debate. Harrison et al. (2009) provide a summary of many current hypotheses and note that while many GCMs are able to produce a realistic seasonal cycle in the region, modeling groups differ in their explanations of the cause. From their own experiments, Harrison et al. (2009) assert that the equatorial seasonal cycle is caused largely by zonal wind stress and that the influence of meridional wind stress is limited to the very easternmost part of the Pacific. Despite uncertainty in the exact relationships, however, these intermediate forcing mechanisms are all ultimately driven by the annual insolation cycle, so changes in insolation can potentially impact equatorial Pacific seasonality.

The temporal and latitudinal distribution of insolation is controlled by three orbital parameters: eccentricity, obliquity, and the orbital longitude of perihelion, which are the shape of Earth's orbit, the tilt of Earth's rotational axis relative to its orbital axis, and the timing with respect to the seasons of Earth's closest approach to the sun, respectively. Over long periods of time, slow, cyclical variations in these parameters change the distribution of the planet's insolation. While global, annual-mean insolation is not affected by changes in the longitude of perihelion (precession) or obliquity, orbital cycles, collectively known as Milankovitch cycles, have likely controlled the timing of glacial-interglacial cycles throughout the Quaternary (Hays et al. 1976) and affected such disparate aspects of the climate system as monsoon strength (Wang et al. 2008; Prell and Kutzbach 1987) and methane emissions (Loulergue et al. 2008).

Several studies concerning the effect of orbital forcing on equatorial Pacific seasonality have already been conducted. Clement et al. (1999) forced climate with the accelerated orbital variations of the past $150 \mathrm{ka}$ in a simplified ocean-atmosphere model and found that Milankovitch cycles affected annual-mean equatorial Pacific SSTs through changes in the seasonal cycle. Timmermann et al. (2007) performed a simulation covering from $142 \mathrm{ka}$ before present to approximately $23 \mathrm{ka}$ after present with accelerated orbital forcing and found that equatorial Pacific seasonality is largely affected by precession through relationships with cloudiness and meridional temperature gradient. The influence of obliquity was primarily limited to changes in the annual mean state. Ashkenazy et al. (2010) conducted simulations at 201 and $213 \mathrm{ka}$, times when perihelion occurred near the vernal and autumnal equinox, respectively, so that equatorial insolation was characterized more by annual, rather than semiannual, cycles in both cases. They found that equatorial Pacific SSTs largely followed the given insolation pattern, with times of maximum and minimum SST lagging times of maximum and minimum insolation by a month or two, though some aspects of the response were likely influenced by air-sea interactions. Luan et al. (2012) forced the climate with the orbital configuration of the Early Holocene and mid-Holocene and found that eastern equatorial Pacific seasonality was controlled by a combination of direct solar forcing and propagation of thermocline anomalies from the west. Furthermore, Luan et al. (2012) suggested that ENSO timing and magnitude are related to the strength of the seasonal cycle. Braconnot et al. (2012) presented some additional analysis of the relationship between equatorial Pacific seasonality and ENSO. More recently, Karamperidou et al. (2015) analyzed the response of ENSO and the seasonal cycle in a mid-Holocene simulation and found reduced eastern equatorial Pacific seasonality due to an "annual Kelvin wave" response forced by western $\mathrm{Pa}$ cific wind anomalies.

The present study takes a different approach from the experiments described above, focusing on a simplified experimental design to target the influence of orbital variations. Instead of varying the three orbital cycles together, this study conducts idealized experiments in 
TABLE 1. Orbital values for the snapshot, precession, and obliquity simulations. Preindustrial and mid-Holocene simulations have forcings from the year 1860 and $6 \mathrm{ka}$, respectively. The first four precession simulations represent times with perihelion at the $\mathrm{NH}$ autumnal equinox (AE), winter solstice (WS), vernal equinox (VE), and summer solstice (SS), with increased eccentricity to amplify the signal. The zero eccentricity simulation has a perfectly circular orbit and therefore no perihelion. Obliquity simulations represent low and high obliquity of the past $600 \mathrm{ka}$ (Berger and Loutre 1991). Dashes indicate values identical to the preindustrial. For a schematic of orbital changes, see Fig. 1 of frequently asked question (FAQ) 6.1 and Fig. 1 in Jansen et al. (2007). Two different preindustrial simulations are used to account for the small differences between the models used for the 6-ka (CM2.1) and precession (CM2.1R) simulations.

\begin{tabular}{lccc}
\hline \hline & Eccentricity & Longitude of perihelion & Obliquity \\
\hline Preindustrial (1860) & 0.01671 & $102.932^{\circ}$ & $23.439^{\circ}$ \\
Mid-Holocene (6 ka) & 0.0187 & $0.87^{\circ}$ & $24.105^{\circ}$ \\
AE & 0.0493 & $0^{\circ}$ & - \\
WS & 0.0493 & $90^{\circ}$ & - \\
VE & 0.0493 & $180^{\circ}$ & - \\
SS & 0.0493 & $270^{\circ}$ & - \\
Zero eccentricity & 0.0 & - & $22.079^{\circ}$ \\
Low obliquity & - & - & $24.480^{\circ}$ \\
High obliquity & - & & \\
\hline
\end{tabular}

which obliquity or the longitude of perihelion (and eccentricity) are varied alone, allowing the climate response to orbital cycles to be isolated and explored. By setting all nonorbital forcings to preindustrial levels, the potential competing effects of changes in ice sheet extent and atmospheric composition are also excluded. Furthermore, unlike the studies mentioned above, complementary simulations with a slab ocean model are used to distinguish the relative importance of ocean dynamical processes in producing the modeled changes. Analysis of simulations from phase 5 of the Coupled Model Intercomparison Project (CMIP5) tests the robustness of the results.

Section 2 of this paper describes the experimental design response of equatorial Pacific seasonality to precession is explored in section 3, and section 4 investigates the response of seasonality to obliquity. In section 5 , these results are compared to output from mid-Holocene simulations in CMIP5 models. Section 6 states the paper's conclusions and provides additional discussion as well as some implications for analysis of paleo-ENSO in proxy records.

\section{Experimental design}

The primary model used in this research is the Geophysical Fluid Dynamics Laboratory (GFDL) Climate Model, version 2.1 (CM2.1), a coupled atmosphereocean GCM with no flux adjustments. Horizontal resolution is $2^{\circ}$ latitude by $2.5^{\circ}$ longitude in the atmosphere and $1^{\circ}$ by $1^{\circ}$ in the ocean, with the oceanic resolution becoming finer in the tropics to a meridional resolution of $1 / 3^{\circ}$ near the equator (Delworth et al. 2006). Reichler and Kim (2008) and Knutti et al. (2013) found that CM2.1 produced one of the most realistic preindustrial climates among models from phase 3 of the Coupled Model Intercomparison Project (CMIP3). Even relative to the more recent CMIP5 models, the simulation would have ranked in the top half based on the Knutti et al. (2013) evaluation.

In the equatorial Pacific, a CM2.1 control simulation compares well against observations, accurately capturing many aspects of equatorial Pacific climatology while showing relatively few biases (Wittenberg et al. 2006). Compared to other CMIP3 models, CM2.1 performs better than many models at reproducing the annual mean and seasonal range of tropical zonal winds and is among the best models at simulating realistic ENSO variability (van Oldenborgh et al. 2005; Capotondi et al. 2006; Merryfield 2006; Joseph and Nigam 2006; Reichler and Kim 2008; Guilyardi et al. 2009; Kug et al. 2010). One difficulty with CM2.1's simulation of the equatorial Pacific is the so-called double ITCZ problem (Wittenberg et al. 2006), in which the intertropical convergence zone (ITCZ) has a northern and southern component. The CM2.1 produces too much precipitation near $10^{\circ} \mathrm{S}$ in the Pacific during boreal spring and the surrounding months. However, the double ITCZ problem is common to many GCMs (Lin 2007), so the present results would likely not be improved by switching to a different model of the same generation.

To isolate the effects of precession and obliquity on equatorial Pacific seasonality, seven idealized equilibrium simulations have been conducted, five for precession and two for obliquity (Table 1). A preindustrial simulation is used for control purposes, and a midHolocene simulation is used for comparison in section 5. In four of the precession simulations, perihelion is set to the Northern Hemisphere (NH) autumnal equinox (AE), winter solstice (WS), vernal equinox (VE), and 
summer solstice (SS), respectively, with all nonorbital forcings, such as ice sheet extent and atmospheric composition, prescribed at preindustrial levels. Eccentricity in these simulations is increased to 0.0493 , the maximum eccentricity of the past $600 \mathrm{ka}$ (Berger and Loutre 1991), to raise the signal-to-noise ratio in the precession results. In the final precession simulation, eccentricity is set to 0 , eliminating any possible climatic effect of precession. This zero eccentricity simulation is used as a point of comparison for the preindustrial simulation. The two obliquity simulations set obliquity to the low $\left(22.079^{\circ}\right)$ and high $\left(24.480^{\circ}\right)$ extremes of the past $600 \mathrm{ka}$, with all other forcings, including eccentricity and the longitude of perihelion, prescribed at preindustrial levels. These simulations were previously analyzed in Mantsis et al. (2011) and Erb et al. (2013), which explored radiative feedbacks, and in Mantsis et al. (2014), which looked at the effect of changes in obliquity on large-scale circulation patterns. Mantsis et al. (2013) examined the response of subtropical anticyclones to precession in a similar set of experiments. Erb et al. (2015) explores the degree to which the climate responses in these singleforcing experiments are consistent with responses in snapshot experiments at the mid-Holocene and Last Glacial Maximum.

To better isolate and understand the role of ocean dynamics in the CM2.1 simulations, a second set of simulations was run on a slab ocean version of the model described above, herein called SM2.1. The atmosphere and ice components in SM2.1 are identical to those in CM2.1, but they are coupled to a single-layer slab ocean with a fixed depth of $50 \mathrm{~m}$ that exchanges heat and moisture with the atmosphere but has no horizontal or vertical transport. A repeating seasonally and spatially varying climatology of heat fluxes is prescribed to account for the missing oceanic heat transport (Stouffer et al. 2006) and to combat overproduction of sea ice. These heat flux terms are identical across SM2.1 simulations and result in a realistic cold tongue without dictating the climate response to orbital forcing. The land model has also been updated in SM2.1 relative to CM2.1 but still uses prescribed vegetation. Simulations using this slab ocean model are set up in a similar manner to the CM2.1 simulations, consisting of the five precession and two obliquity simulations as well as the preindustrial control run.

As in Erb et al. (2013), a calendar adjustment has been made to the precession results. When the longitude of perihelion is altered under high eccentricity, calendar dates of some solstices and equinoxes become shifted because of Kepler's second law (Joussaume and Braconnot 1997). To account for this, precession results have been converted to a common fixed-angular calendar, where each "month" corresponds to a $30^{\circ}$ arc of orbit. These months range from 28 to 33 days. The conversion was made using the method outlined in Pollard and Reusch (2002), which is one of several proposed methods (Timm et al. 2008; Chen et al. 2011).

For the CM2.1 orbital forcing simulations, results in this paper use the mean climatology of years 501-600 from the simulations. A slightly updated version of CM2.1 code (CM2.1R) was used to run the precession simulations, but these small model differences are unlikely to affect the conclusions. SM2.1 simulations were run for 100 years, and results in this paper use climatologies of the last 50 years.

\section{Effects of precession on equatorial Pacific seasonality}

Precession, which has periodicities around $20 \mathrm{ka}$, alters the timing of perihelion, increasing insolation during approximately half of the year and decreasing it during the other half. At present, perihelion occurs in the first week of January, so equatorial insolation is slightly higher in boreal winter than boreal summer, though both seasons have reduced equatorial insolation compared to the equinoxes, when solar radiation intercepts the tropics at a lower mean zenith angle. The gradual shift in the longitude of perihelion determines which season has increased insolation resulting from closer proximity to the sun, an effect that is amplified by high eccentricity in the precession simulations (Fig. 1). Simulations with perihelion at the $\mathrm{AE}$ and $\mathrm{VE}$ are characterized by a sharp equatorial insolation maximum at that equinox and a flatter double minimum during the opposite time of year. The simulations with perihelion at WS and SS have flatter insolation maxima and sharper minima. In all four of these cases, the enhanced eccentricity results in seasonal insolation distributions in the tropics that are more annual in their period, rather than more semiannual as in the preindustrial simulation. Annual insolation anomalies at $6 \mathrm{ka}$, which will be discussed in section 5 , are similar to AE because the timing of perihelion is similar, although eccentricity is lower. In the zero eccentricity simulation, equatorial insolation has no annual component, instead having a semiannual cycle with maxima at the two equinoxes. Maximum monthly TOA equatorial insolation anomalies between preindustrial and the four precession simulations are approximately $50 \mathrm{~W} \mathrm{~m}^{-2}$, which is a change of about $10 \%$ of the total insolation. Among the four precession simulations, insolation anomalies can reach approximately $80 \mathrm{~W} \mathrm{~m}^{-2}$.

\section{a. CM2.1 simulations}

The present-day equatorial Pacific SST cycle is marked by strong seasonal variation in the east, with 

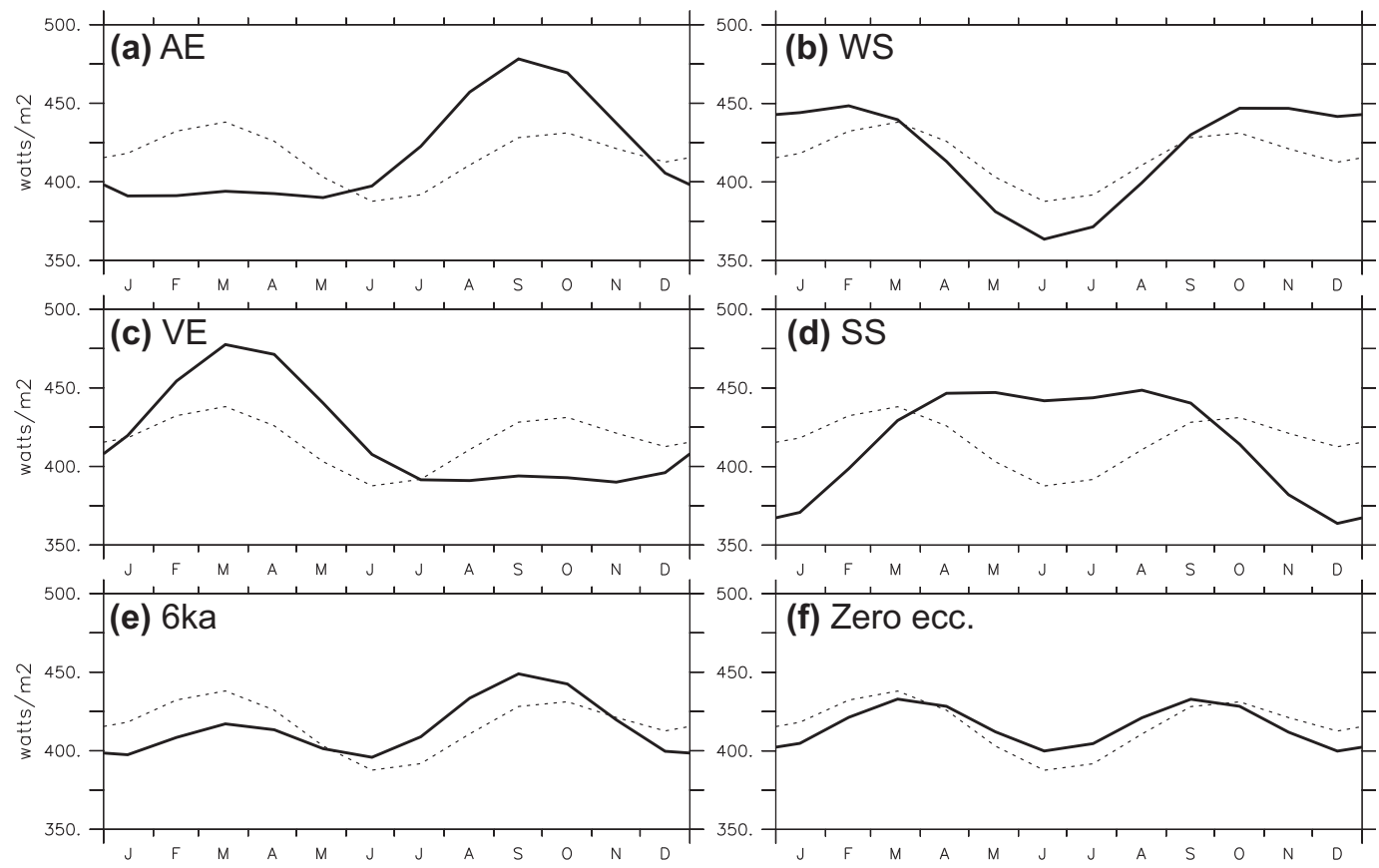

FIG. 1. Mean $5^{\circ} \mathrm{S}-5^{\circ} \mathrm{N}$ incoming shortwave radiation at TOA $\left(\mathrm{W} \mathrm{m}^{-2}\right.$ ) for (a) AE, (b) WS, (c) VE, (d) SS, (e) 6-ka, and (f) zero eccentricity simulations. Preindustrial insolation is shown as a dotted line in each panel. Note that $\mathrm{AE}$ and 6-ka simulations have similar longitudes of perihelion, but eccentricity is increased for AE, amplifying the anomalies.

maximum temperatures in boreal spring and minimum temperatures in boreal summer and autumn, as can be seen in the ERSST.v3b observational dataset (Fig. 2a) (Smith et al. 2008). Temperatures farther west in the equatorial Pacific have extrema that are generally delayed by several months, exhibit much less seasonal variation, and are several degrees warmer overall. In the CM2.1 preindustrial simulation, despite a cold tongue that extends too far west and is too cold throughout the year, the general pattern of seasonal variation is (a) Observations

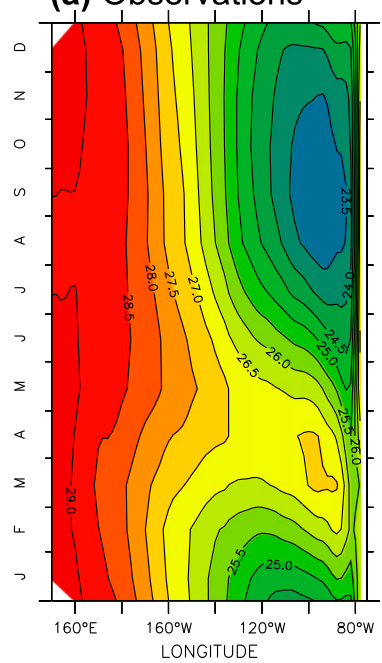

(b) Preindustrial

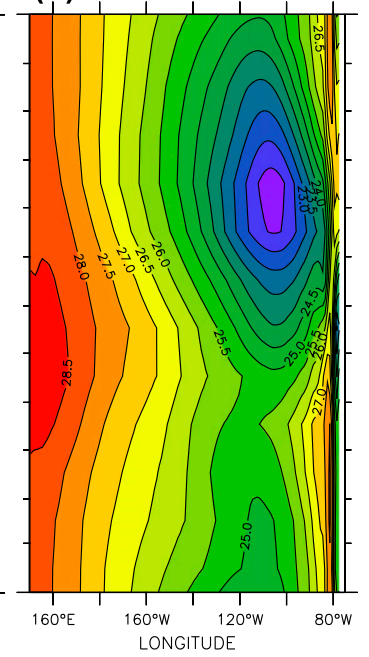

(c) Zero ecc.

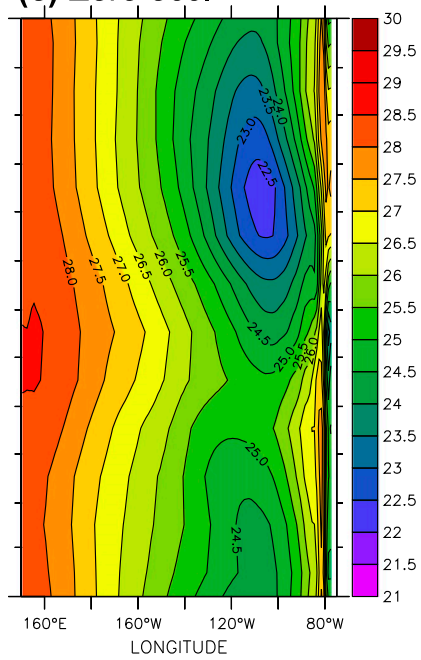

(d) Preind - zero ecc.

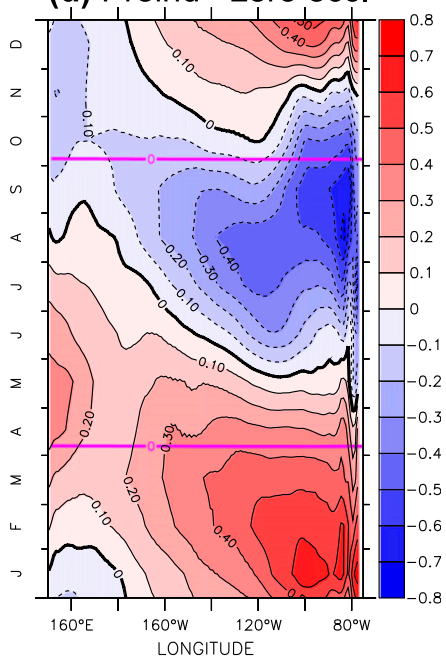

FIG. 2. Longitude-time plots of mean $5^{\circ} \mathrm{S}-5^{\circ} \mathrm{N}$ Pacific SSTs $\left({ }^{\circ} \mathrm{C}\right.$ ) for (a) ERSST.v3b observations from 1854 to 1953 as well as (b) preindustrial and (c) zero eccentricity CM2.1 simulations. (d) Difference between the preindustrial and zero eccentricity simulations, with magenta lines indicating the boundaries between positive and negative insolation forcing. 
(a) AE - preind

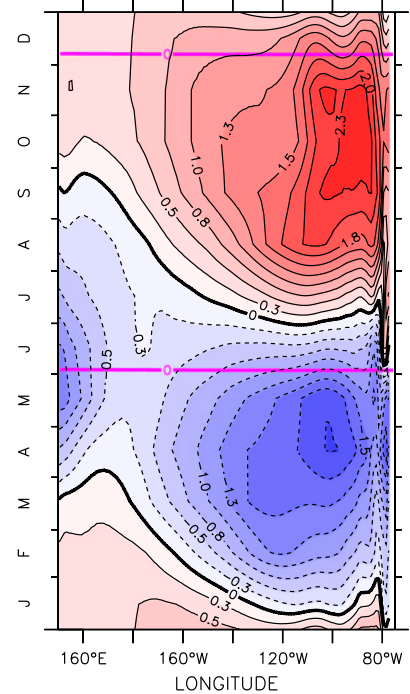

(e) $\mathrm{AE}$

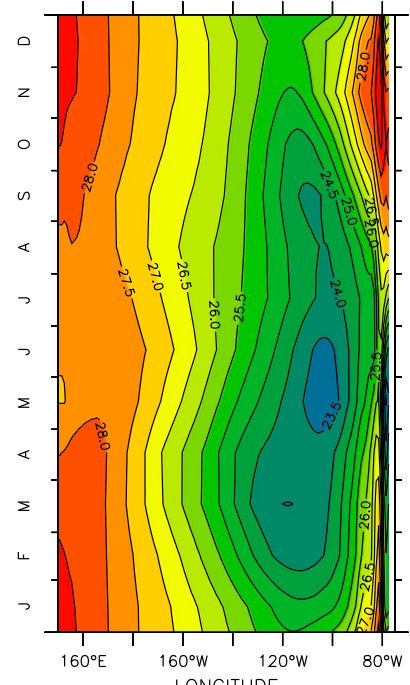

(b) WS - preind

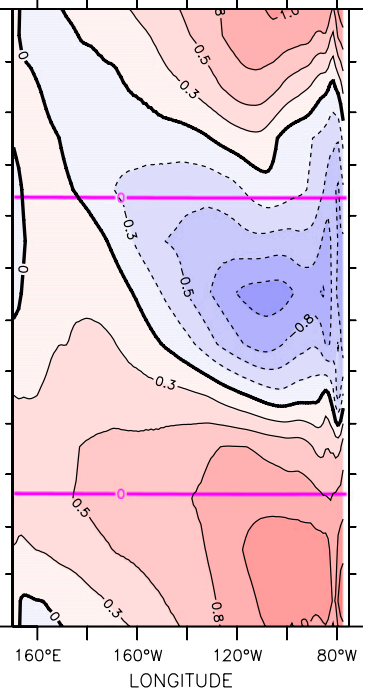

(f) WS

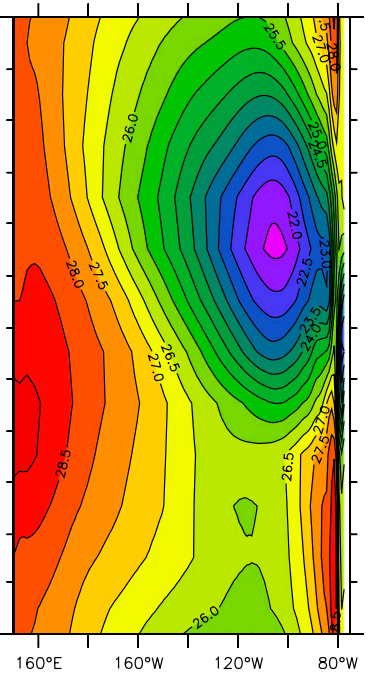

(c) VE - preind

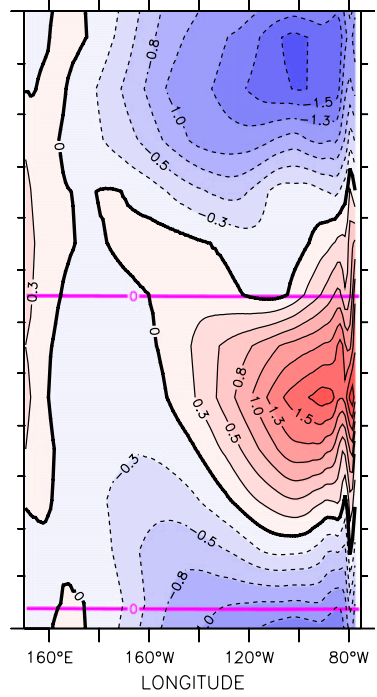

(g) VE

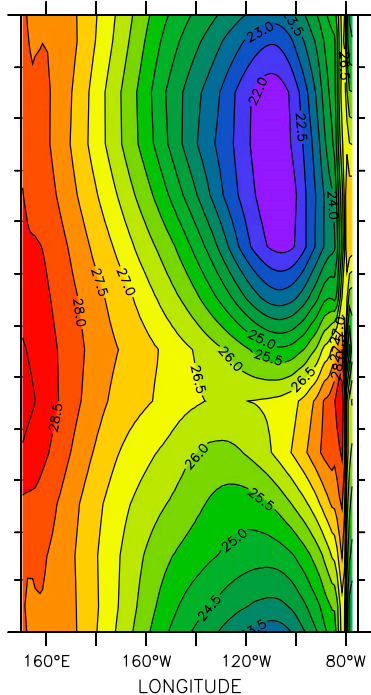

(d) SS - preind

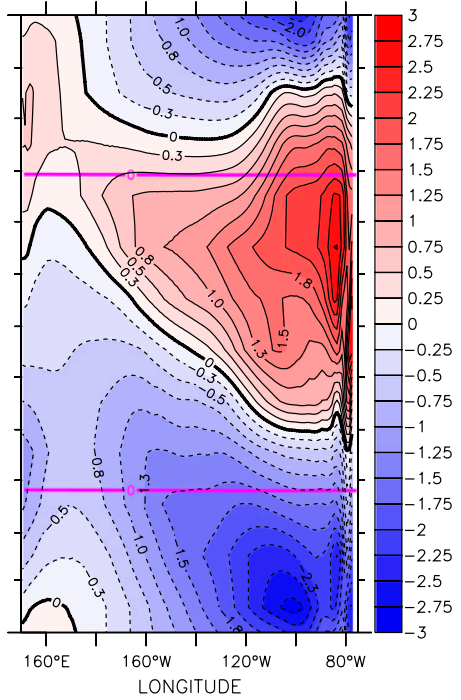

(h) SS

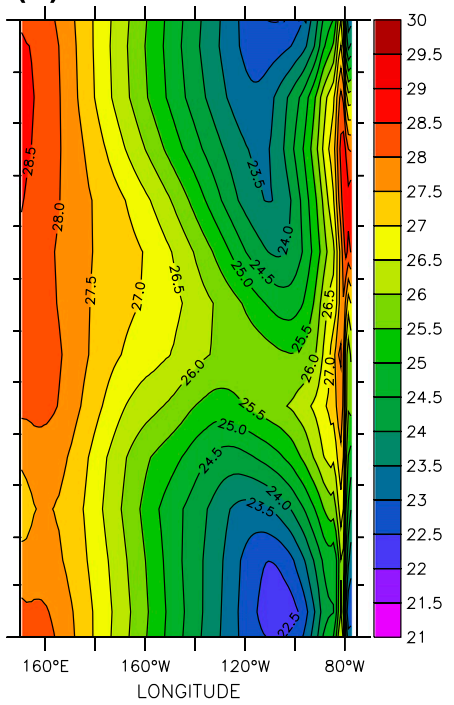

FIG. 3. Longitude-time plots of change relative to the CM2.1 preindustrial control run in mean $5^{\circ} \mathrm{S}-5^{\circ} \mathrm{N}$ Pacific SSTs $\left({ }^{\circ} \mathrm{C}\right)$ for (a) AE, (b) WS, (c) VE, and (d) SS. Magenta lines indicate boundaries between positive and negative insolation forcing. Note how the largest SST anomalies in the eastern Pacific precede these insolation sign changes, suggesting indirect response mechanisms are at work. Absolute SSTs are also shown for (e) AE, (f) WS, (g) VE, and (h) SS.

simulated relatively well (Fig. 2b). Compared to the zero eccentricity simulation (Figs. 2c,d), seasonality at preindustrial is a bit stronger, with SSTs that are up to about $0.5^{\circ} \mathrm{C}$ warmer during boreal winter and approximately $0.5^{\circ} \mathrm{C}$ cooler during boreal summer and autumn in the eastern equatorial Pacific. Interestingly, the SST change between preindustrial and zero eccentricity is not uniform across the Pacific despite zonally uniform TOA insolation forcing. To explore the influence of precession on SST seasonality more comprehensively, the remaining CM2.1 precession simulations are compared against the preindustrial simulation to see how precession affects the timing, magnitude, and character of the SST response (Fig. 3). Changes in annual-mean SST in the tropics are generally relatively small in these precession experiments, being the residual of larger seasonal changes of opposite sign, and they will not be the focus of this research.

One of the simulations most similar to preindustrial in the timing of SST maxima and minima is WS (perihelion at NH winter solstice; Figs. 3b,f), which is also the simulation with the most similar orbit; the orbital longitude 


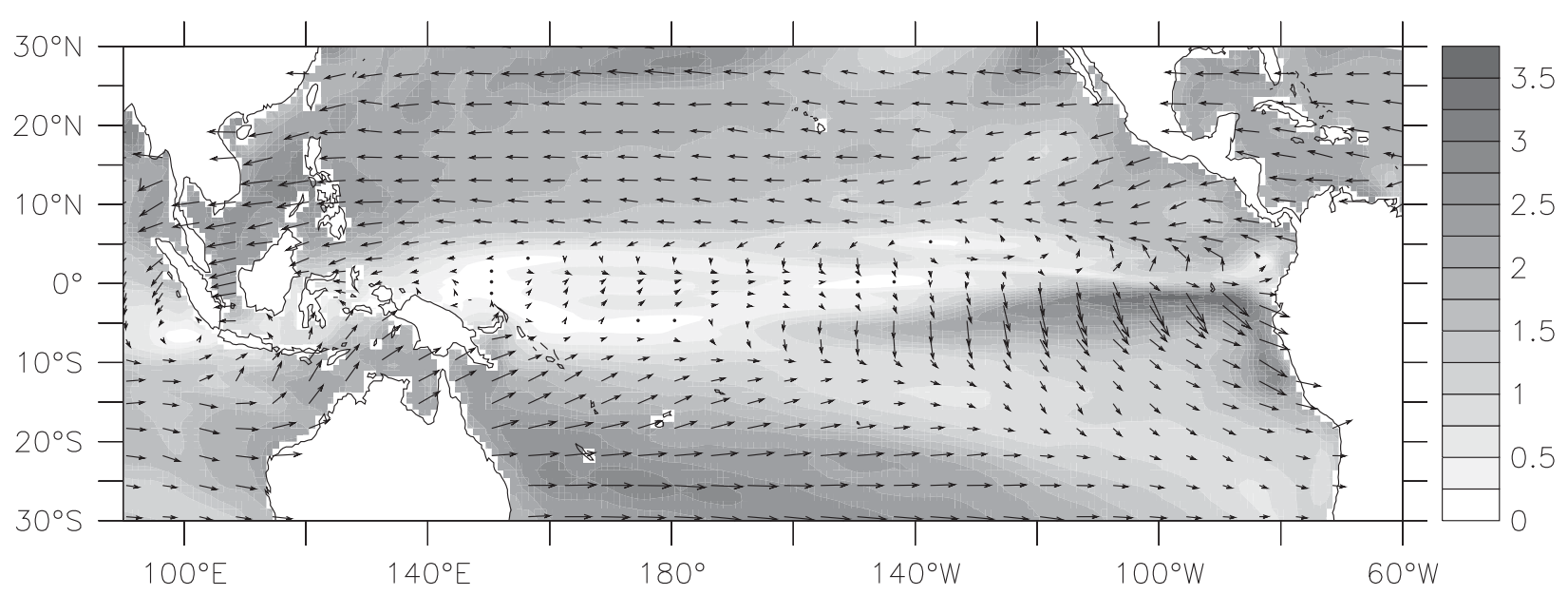

\section{Vector Key}

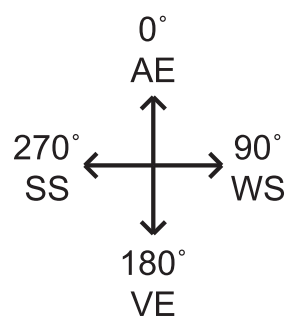

FIG. 4. The longitude of perihelion of maximum seasonality (vectors), computed by fitting a first harmonic to the annual SST ranges (warmest month minus coldest month) of the four precession simulations. As indicated on the key, vectors pointing toward north, east, south, and west represent maximum seasonality at longitudes of perihelion of $0^{\circ}(\mathrm{AE}), 90^{\circ}(\mathrm{WS}), 180^{\circ}(\mathrm{VE})$, and $270^{\circ}(\mathrm{SS})$, respectively. Shading (and vector length) shows the amplitude of the harmonic $\left({ }^{\circ} \mathrm{C}\right)$ so that darker gray represents areas where the magnitude of SST seasonality responds more strongly to precession.

of perihelion is $102.9^{\circ}$ in the preindustrial simulation and $90.0^{\circ}$ in the WS simulation. Since seasonality is stronger at preindustrial than in the zero eccentricity simulation, it is unsurprising to see that WS, where an increase in eccentricity is the primary change, has an even stronger seasonal SST cycle. Eastern Pacific SSTs are approximately $1^{\circ} \mathrm{C}$ warmer than preindustrial in boreal winter and up to about $1^{\circ} \mathrm{C}$ cooler than preindustrial in boreal summer. Changes in the western Pacific are smaller, with the largest change being a warming of up to about $0.4^{\circ} \mathrm{C}$ in boreal spring. Compared to preindustrial, maximum and minimum SSTs generally occur a few weeks earlier in the year.

The VE simulation (perihelion at $\mathrm{NH}$ vernal equinox), with a longitude of perihelion of $180^{\circ}$, also displays a strengthening of the seasonal SST cycle, with maximum and minimum temperatures about a few weeks later in the year compared to preindustrial (Figs. 3c,g). Of the precession simulations, VE displays the largest seasonality over much of the eastern equatorial Pacific, with an amplitude $>5^{\circ} \mathrm{C}$ between boreal spring and autumn. Since these simulations are limited to four distinct moments during the precessional cycle, however, it is unlikely that the longitude of perihelion that produces maximum seasonality has been simulated. Assuming that the magnitude of seasonality at each location follows a sinusoidal trend over the course of a full precession cycle (which is a simplification, but a useful one), then fitting the first harmonic of a Fourier series to the four simulations should approximate the longitude of perihelion that produces maximum seasonality (the greatest difference between warmest month and coldest month) at each location (Fig. 4). In the northern and southern extratropical Pacific Ocean, maximum SST seasonality occurs when perihelion reinforces the natural tilt-forced insolation cycle, which happens when the longitude of perihelion is near $270^{\circ}$ (SS) in the Northern Hemisphere and $90^{\circ}$ (WS) in the Southern Hemisphere. In the tropics, however, a more complex pattern emerges. Throughout most of the western Pacific warm pool, changes in the longitude of perihelion have only a small effect on the magnitude of seasonality. In the eastern Pacific there is a mixed response from approximately $0^{\circ}$ to $5^{\circ} \mathrm{N}$ but a strong response just south of the equator, with maximum seasonality occurring with perihelion shortly before the vernal equinox. In the Niño-3 region, this corresponds with a longitude of perihelion of about $155^{\circ}$. In other words, maximum seasonality in that region should occur when the date of perihelion is roughly a month before $\mathrm{NH}$ vernal equinox. Because present-day perihelion is slowly becoming later in the year, this simple analysis suggests that, if acting alone, precession would cause the eastern equatorial Pacific seasonality to slightly increase in strength over the next three millennia. 
(a) $A E$ - preind

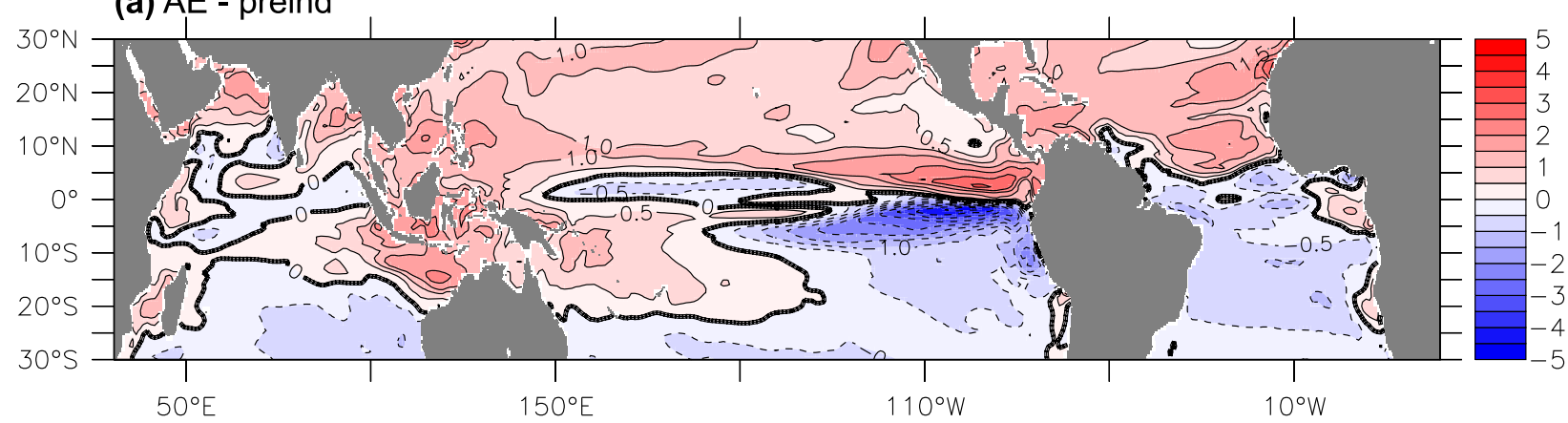

(b) Lo - Hi obliquity

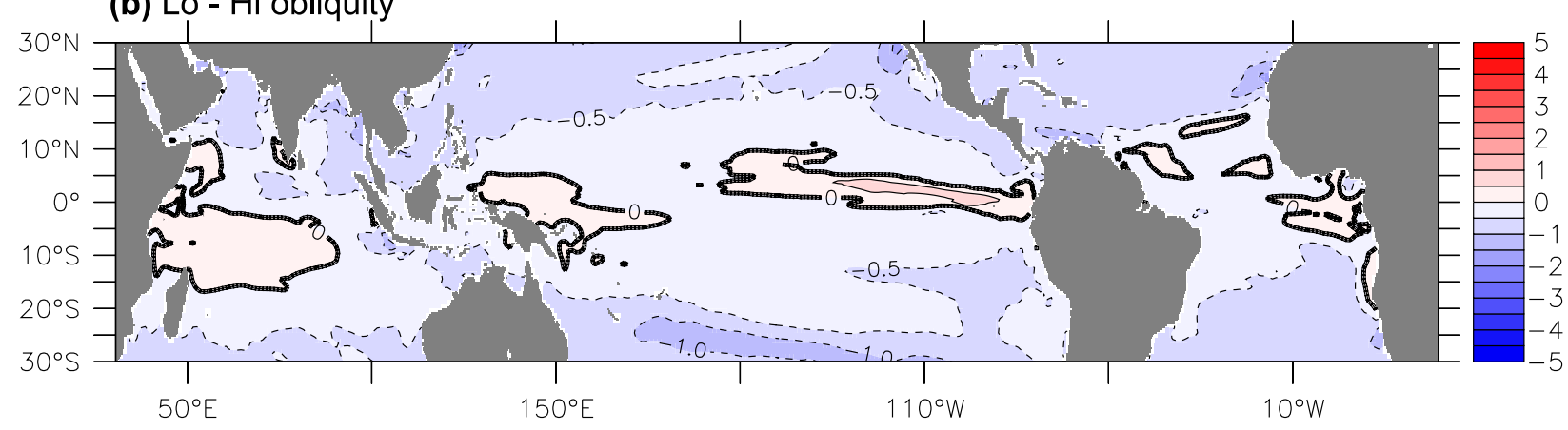

FIG. 5. Change in annual temperature range $\left({ }^{\circ} \mathrm{C}\right)$, defined as the max minus min monthly mean SST at each location, for the (a) AE-preind and (b) low-high (Lo-Hi) obliquity experiments.

In contrast with the WS and VE simulations, which generally have increased seasonality compared to preindustrial, the main response in the SS simulation (perihelion at $\mathrm{NH}$ summer solstice) is a shift in the timing of maximum and minimum SSTs (Figs. 3d,h). In the eastern equatorial Pacific, minimum SST in the SS simulation occurs in January, a change of four months from the preindustrial simulation, while maximum SST occurs in May or June for most of the region, a change of only one or two months from the preindustrial simulation.

The final precession experiment, AE (perihelion at $\mathrm{NH}$ autumnal equinox), is the only one that displays reduced seasonality compared to preindustrial in much of the equatorial Pacific cold tongue (Fig. 5a). Relative to the preindustrial experiment, the eastern equatorial Pacific in AE shows a cooling of up to about $2^{\circ} \mathrm{C}$ in April and a warming of about $2^{\circ} \mathrm{C}$ in August-November, flattening out the seasonal cycle to a large extent (Figs. 3a,e). Similar temperature variations also account for the increase in seasonality just north of the equator (Fig. 5a); the preindustrial seasonal cycle is weak in that region, so the temperature changes are actually big enough to promote a seasonal cycle with different timing than south of the equator. Compared to the eastern equatorial Pacific, temperature changes in the western Pacific warm pool are smaller in magnitude and a few months later in the year, despite the zonally uniform insolation forcing. This asynchronous temperature response between the eastern and western Pacific is present not just in the AE minus preindustrial (AEpreind) experiment but in all four precession experiments; almost without exception, temperature changes in the eastern equatorial Pacific are larger in magnitude and precede temperature changes in the west. When comparing the timing of these anomalies with TOA insolation anomalies (magenta lines in Figs. 3a-d), the maximum SST anomalies in the west coincide with the boundaries between positive and negative insolation forcing, which would be expected for a direct thermodynamic response to TOA insolation. In the east, however, maximum SST anomalies precede these boundaries. This early response illustrates that SST changes are not a simple thermodynamic response to changes in insolation everywhere in the equatorial Pacific. As a point of comparison, the next section explores the climate response to precession in the slab ocean model.

\section{b. SM2.1 simulations}

SM2.1 lacks explicit vertical or horizontal ocean transport; the climatological impact of ocean heat transports are approximated through a prescribed, climatological heat flux that varies both spatially and with 
(a) Observations

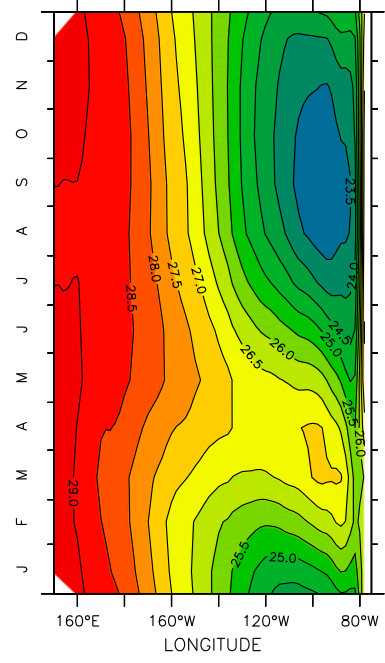

(b) Preindustrial

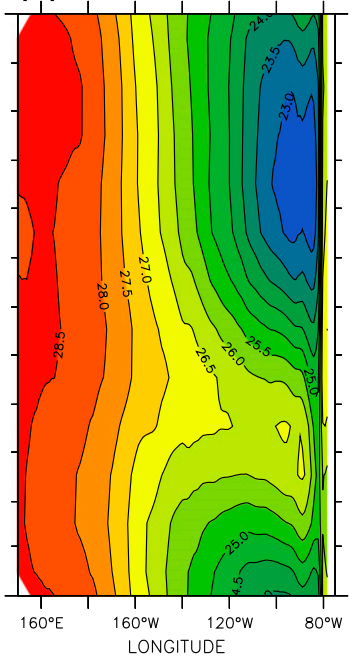

(c) Zero ecc.

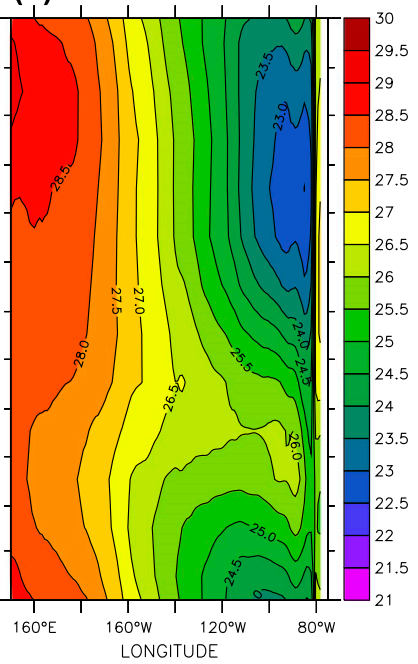

(d) Preind - zero ecc.

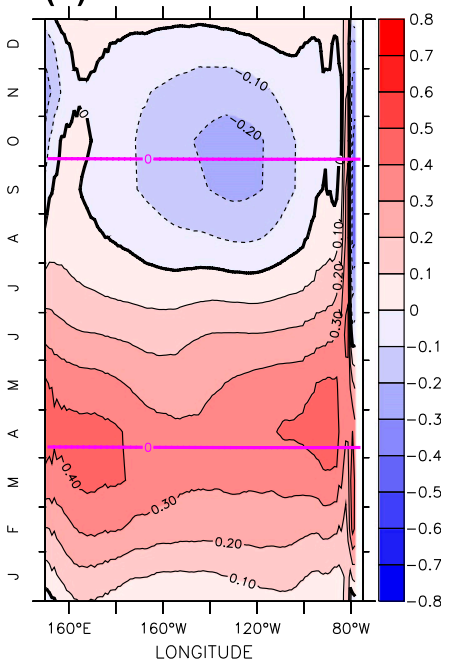

FIG. 6. As in Fig. 2, but for SM2.1 simulations in (b)-(d).

month, so the climate response to precessional forcing is determined by the local response of the mixed layer to atmospheric processes and surface fluxes alone. Because of this, a comparison between CM2.1 and SM2.1 results should help reveal the role of ocean dynamics in shaping the climate response to orbital forcing.

The SST pattern in the SM2.1 preindustrial simulation (Fig. 6b) is characterized by maximum eastern equatorial Pacific warmth during boreal spring and cooler SSTs during the latter half of the year. This temperature pattern closely matches observed SSTs in the ERSST.v3b temperature dataset (Fig. 6a), helped by the prescribed heat flux that approximates the impact of real ocean heat transport. The equatorial Pacific SST pattern in the SM2.1 preindustrial simulation is generally more realistic than that in the CM2.1 preindustrial simulation, but it is unclear to what extent this difference in climatology between the two models affects the climate changes in perturbation experiments. Compared to the zero eccentricity simulation (Fig. 6c), preindustrial SSTs in the SM2.1 are warmer during boreal spring and generally cooler during boreal autumn in the equatorial Pacific (Fig. 6d). The sign of this temperature response is relatively zonally uniform across the basin, with some of the nonuniformity resulting from changes in cloud amount.

Compared to preindustrial, SST anomalies in each of the four remaining precession simulations are positive during the half-year beginning within approximately one month of perihelion and negative during the other half of the year (Fig. 7). The sign of these changes is somewhat zonally uniform across the Pacific and, because the largest temperature anomalies across the entire Pacific correspond with the boundaries between positive and negative TOA insolation, both the east and west equatorial Pacific appear to respond directly to the insolation forcing.

\section{c. Comparison of CM2.1 and SM2.1 results}

By comparing the CM2.1 (Fig. 3) and SM2.1 (Fig. 7) results, several important differences become clear. Most noticeably, eastern equatorial Pacific SST anomalies in the CM2.1 precession experiments are generally larger in magnitude, and extrema occur up to two or more months earlier in the year compared to SM2.1 results, well before insolation anomalies change sign. CM2.1 anomalies show a distinct zonal asymmetry, while SM2.1 anomalies are much more zonally uniform, with comparatively smaller eastern equatorial Pacific SST anomalies. The models feature identical atmospheric models, so these differences should arise primarily because of the presence or absence of ocean dynamics. While some of the difference in timing may potentially be attributed to the models' differing values of mixed layer depth, which is shallower in the east than the west equatorial Pacific in CM2.1 but constant at $50 \mathrm{~m}$ in SM2.1, the analysis in section 3d indicates that surface heat fluxes are not the primary means of temperature change in the eastern equatorial Pacific in the AE-preind experiment of CM2.1. Therefore, the main response does not appear to simply result from differential lag to a zonally uniform surface forcing. When looked at regionally, the strengthening and advanced timing of the eastern SST anomalies in the CM2.1 is pronounced within a few degrees of the equator, suggesting a robust mechanism 
(a) $A E$ - preind

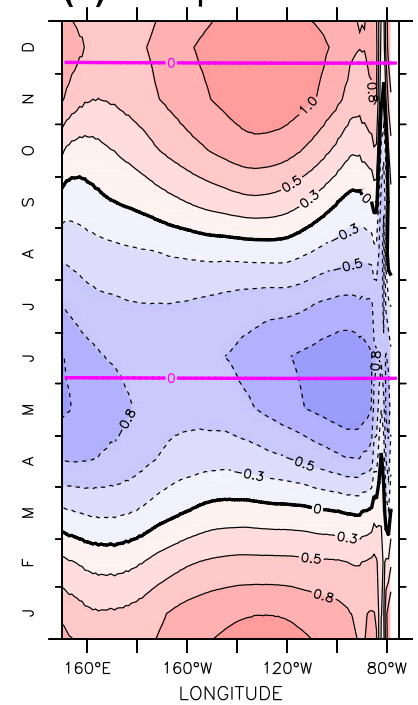

(e) $\mathrm{AE}$

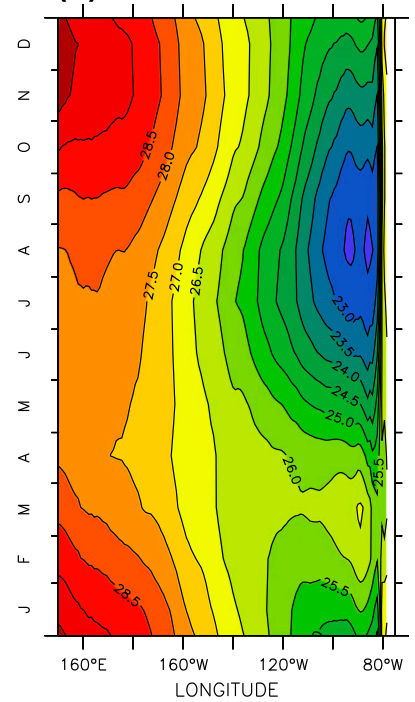

(b) WS - preind

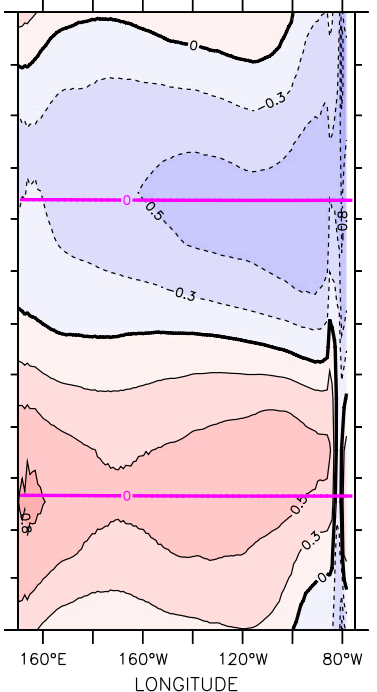

(f) WS

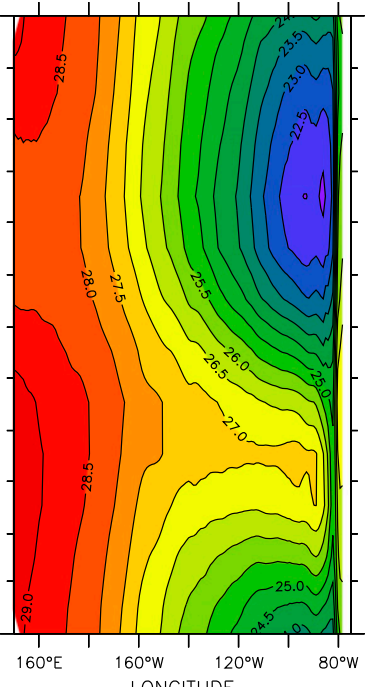

(c) VE - preind

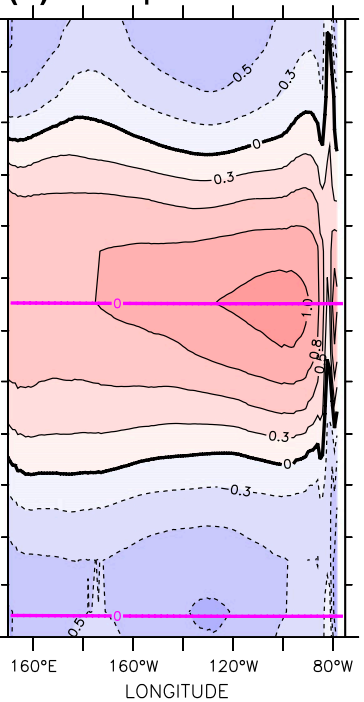

(g) VE

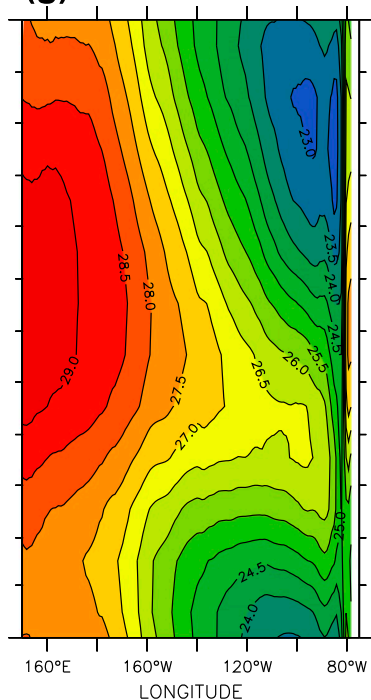

(d) SS - preind

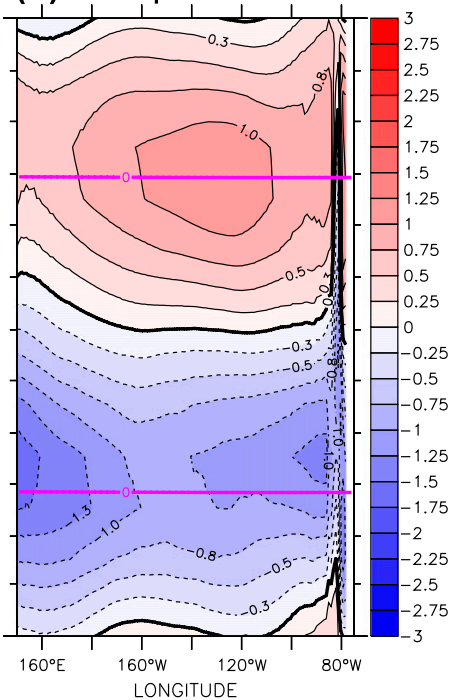

(h) SS

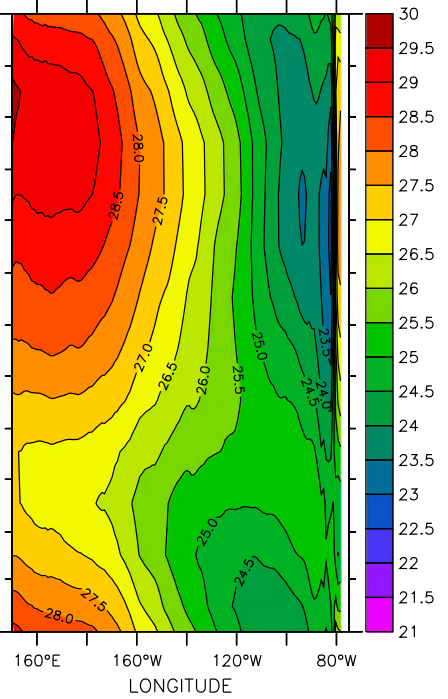

FIG. 7. As in Fig. 3, but for SM2.1 simulations. Note how the largest SST anomalies occur very close to the dates of the insolation sign changes (magenta lines), suggesting a direct thermodynamic response.

in the equatorial ocean. SST anomalies in the western equatorial Pacific show less consistent, but still noticeable, differences between the CM2.1 and SM2.1 results.

\section{d. Mechanisms of change in the CM2.1 autumnal equinox simulation}

Analysis of the causes of differences between the CM2.1 and SM2.1 responses will focus on the AE-preind experiment for the sake of simplicity. Additionally, because the longitude of perihelion in the AE simulation $\left(0^{\circ}\right)$ is similar to the mid-Holocene $\left(0.87^{\circ}\right)$, the $\mathrm{AE}$ simulation provides an interesting analog to a recent time period and will allow for better comparisons to CMIP5 mid-Holocene simulations.

To determine the causes of the asynchronous temperature response in the AE-preind experiment of CM2.1, a heat budget analysis of the near-surface layer is conducted. Following DiNezio et al. (2009), the heat budget is approximated from surface heat fluxes as well as horizontal and vertical ocean heat fluxes over the upper $75 \mathrm{~m}$ of the equatorial Pacific. Temperature changes averaged over the upper $75 \mathrm{~m}$ are shown in Fig. 8a, and the total heat flux necessary to account for this change, calculated from the temperature tendency of this layer, is shown in Fig. 8b. In comparison, the 
(a) $\Delta \mathrm{T}_{0}$

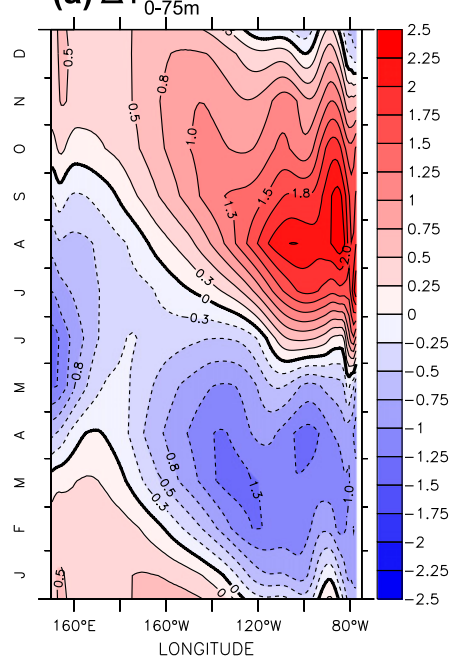

(b) $\Delta Q_{n}$

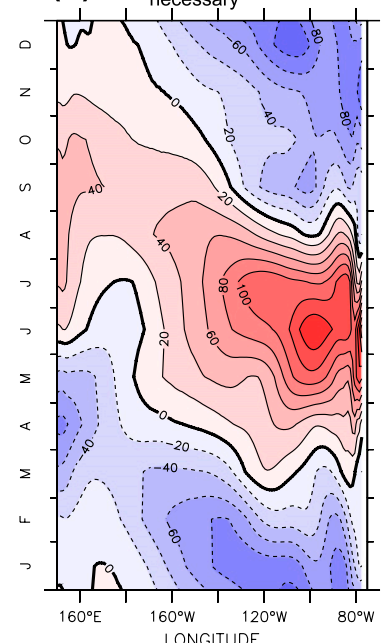

(c) $\Delta \mathrm{Q}$

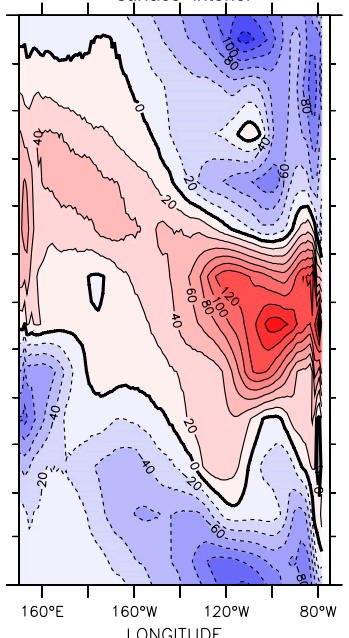

(d) $\Delta Q_{\text {nec. }}-\Delta Q_{\text {surf.tinterior }}$

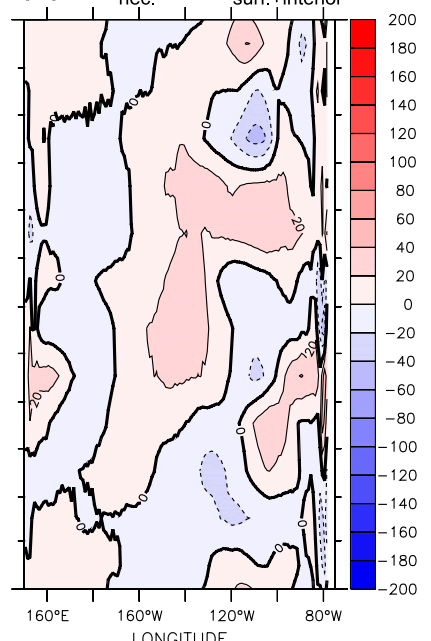

FIG. 8. Longitude-time plots of (a) the change in ocean temperature $\left({ }^{\circ} \mathrm{C}\right)$ for the AE-preind $\mathrm{CM} 2.1$ experiment averaged over $5^{\circ} \mathrm{S}-5^{\circ} \mathrm{N}$ and the upper $75 \mathrm{~m}$ of ocean and (b) the change in heat flux $(\Delta \mathrm{Q})$ necessary to explain this change $\left(\mathrm{W} \mathrm{m}^{-2}\right)$, calculated from the temperature tendency of the layer. (c) The change in heat flux $\left(\mathrm{W} \mathrm{m}^{-2}\right)$ into the layer, calculated from surface and interior ocean fluxes. (d) The heat flux residual $\left(\mathrm{W} \mathrm{m}^{-2}\right)$ is calculated as the difference between (b) and (c).

change in heat flux into this layer, calculated as the sum of the surface heat flux and heat fluxes internal to the ocean, is shown in Fig. 8c. The zonal asymmetry of this heat flux anomaly, in contrast to the zonal uniformity of the TOA insolation anomaly, reinforces the hypothesis that a simple thermodynamic response to changes in TOA insolation is insufficient to explain the entire SST response. The residual between the necessary heat flux and calculated heat flux is small (Fig. 8d), suggesting that processes not included in the heat flux calculations (e.g., vertical diffusion) should not greatly affect the results of this analysis.

The calculated heat flux is broken down into the surface heat flux and the zonal, meridional, and vertical ocean heat fluxes (Fig. 9). To a large extent, the heat fluxes in the western Pacific warm pool are dominated by the surface heat flux, suggesting that temperature (a) $\Delta Q_{\text {surface }}$

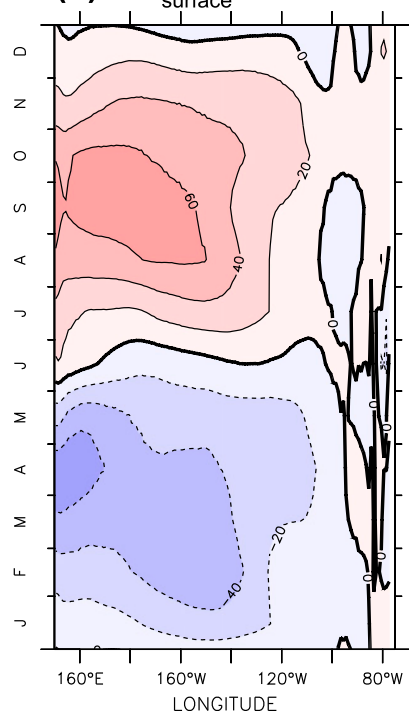

(b) $\Delta Q_{\text {zonal }}$

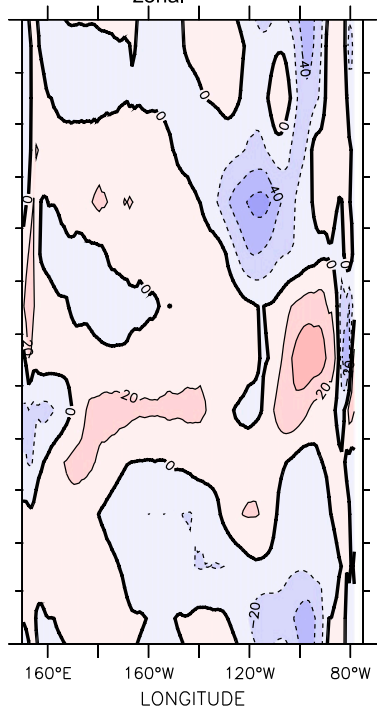

(c) $\Delta Q_{\text {meridional }}$

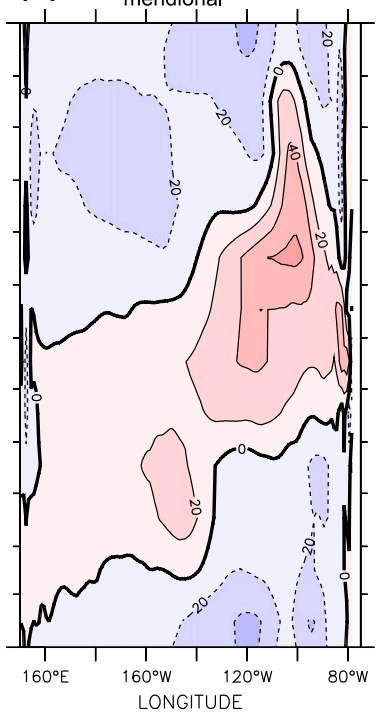

(d) $\Delta Q_{\text {vertical }}$

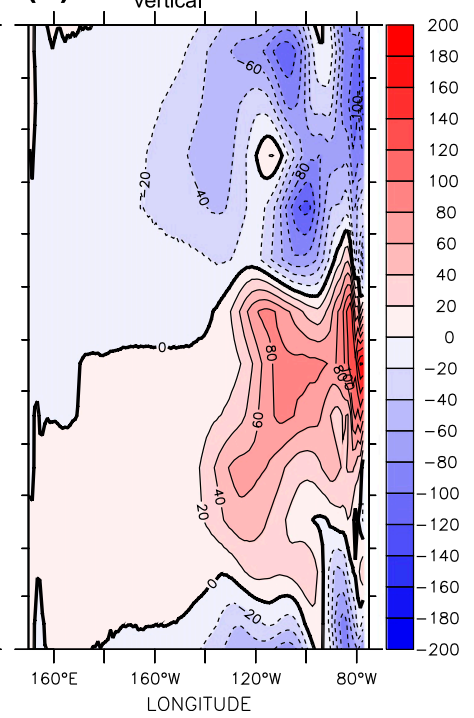

FIG. 9. Longitude-time plots of changes in heat flux $\left(\mathrm{W} \mathrm{m}^{-2}\right)$ averaged over $5^{\circ} \mathrm{S}-5^{\circ} \mathrm{N}$ and the upper $75 \mathrm{~m}$ of the ocean for the AE-preind experiment, resulting from (a) surface heat flux, (b) zonal ocean heat flux, (c) meridional ocean heat flux, and (d) vertical ocean heat flux. Together, these four fluxes equal the total heat flux in Fig. $8 \mathrm{c}$. 

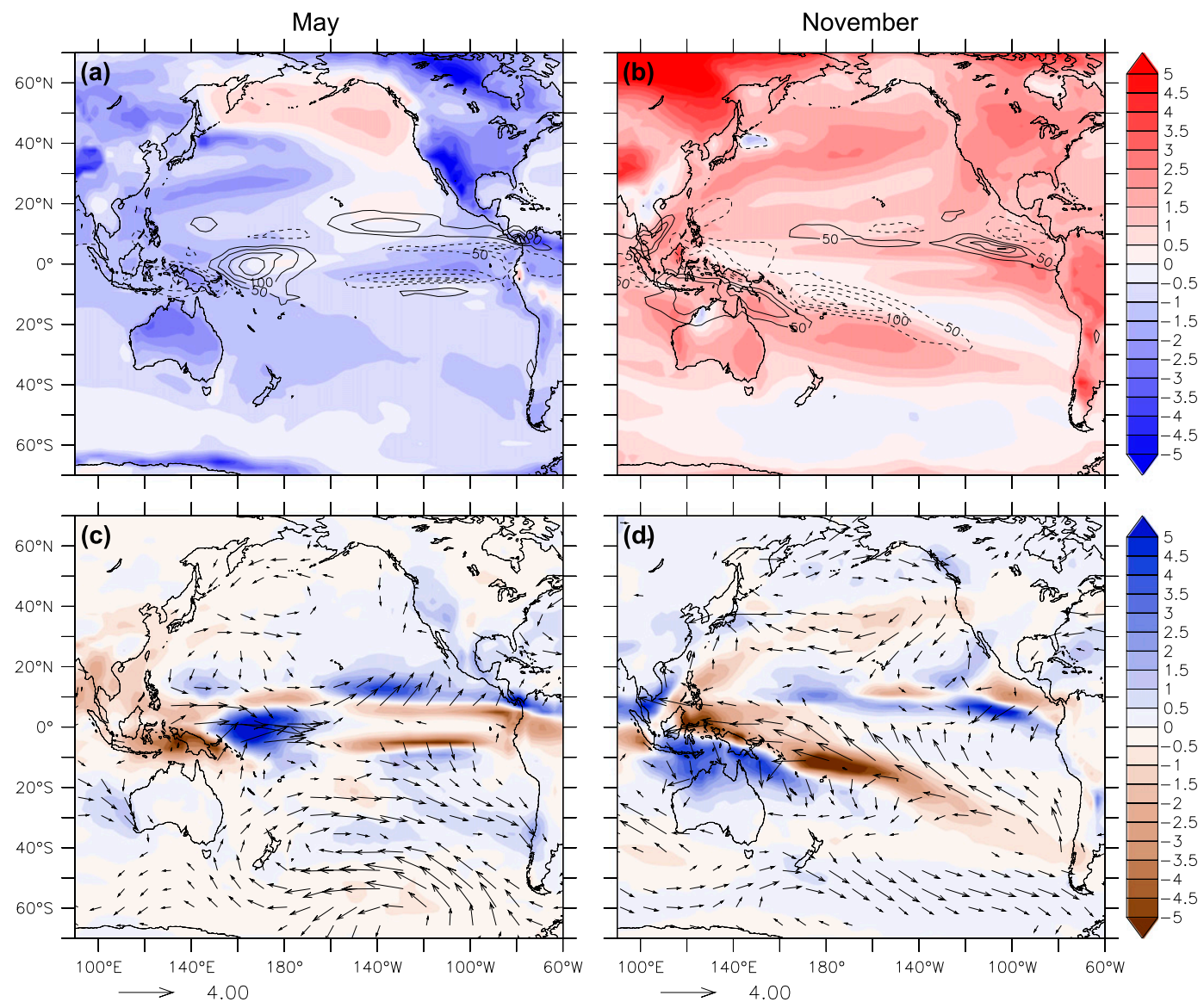

FIG. 10. Change in the surface temperature $\left({ }^{\circ} \mathrm{C}\right.$; shaded) and atmospheric diabatic heating $\left(\mathrm{W} \mathrm{m}^{-2}\right.$; contours) in (a) May and (b) November for the AE-preind experiment. Change in precipitation (shaded; mm day ${ }^{-1}$ ) and $10-\mathrm{m}$ wind (vectors; $\mathrm{m} \mathrm{s}^{-1}$ ) in (c) May and (d) November for the AE-preind experiment. May and November represent approximate months of maximum westerly and easterly wind anomalies in the western equatorial Pacific. Atmospheric diabatic heating is computed as the sum of contributions from shortwave radiation, longwave radiation, convection, stratiform clouds, and sensible heat flux. Heating from convection is generally the largest component. Atmospheric diabatic heating has a contour interval of $50 \mathrm{~W} \mathrm{~m}^{-2}$, with no contour between -50 and $50 \mathrm{~W} \mathrm{~m}^{-2}$. The reference vectors at the bottom show the scale for a change in surface wind of $4 \mathrm{~m} \mathrm{~s}^{-1}$. Wind anomalies smaller than $0.5 \mathrm{~m} \mathrm{~s}^{-1}$ are not shown.

changes in the western equatorial Pacific can be primarily explained as a direct thermodynamic response to changes in insolation. Surface fluxes become much smaller in the east, however, owing largely to changes in clouds and latent heat fluxes, and therefore fail to account for much of the temperature change in that region.

Thus changes in upper-ocean temperature in the eastern equatorial Pacific are primarily driven by changes in zonal, meridional, and vertical ocean heat fluxes (Figs. 9b-d). In the eastern equatorial Pacific, the largest changes are due to the vertical heat flux, but significant fluxes also occur in the zonal and meridional directions. The following analysis suggests that these changes in heat flux occur largely by means of an equatorial thermocline signal propagating from the west, which likely originates through two mechanisms: changes in the strength of the Pacific subtropical anticyclones associated with monsoonal heating anomalies and shifts in convection over the Maritime Continent and western Pacific region.

The subtropical anticyclones in the CM2.1 preindustrial experiment are characterized by high pressure centers in the midlatitude ocean basins near $30^{\circ}-35^{\circ} \mathrm{N}$ (similar to Figs. 19 and 20 of Delworth et al. 2006). In the AE-preind experiments, subtropical anticyclones in the Pacific and Atlantic Oceans are generally weakened in May and strengthened in November. While this change tends to be more pronounced in CM2.1, especially in May, changes of the same sign are seen in most regions in the slab ocean model, indicating that at least part of this response is independent of ocean dynamics. In precession 
(a) January
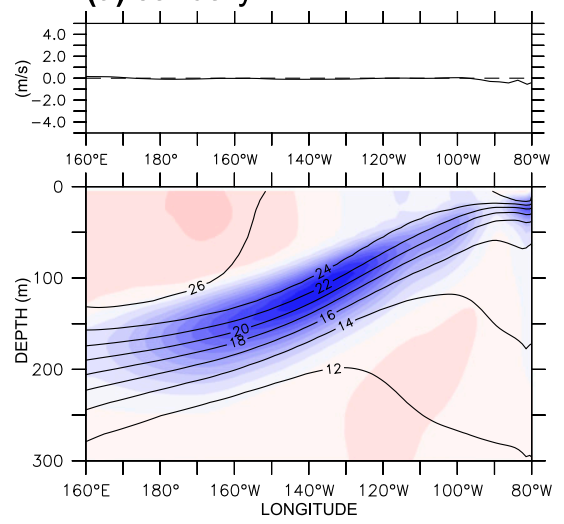

(d) July
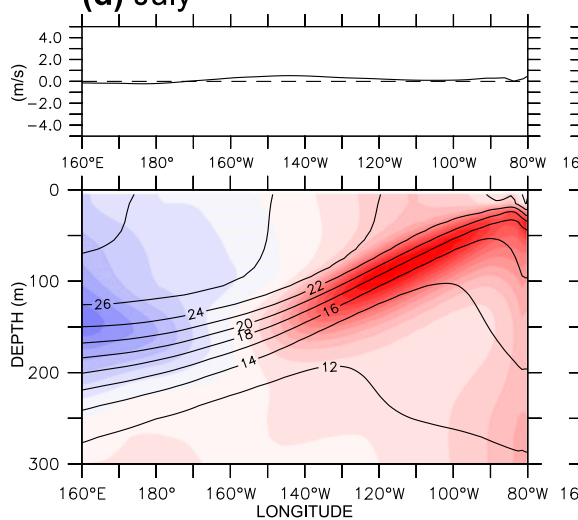

(b) March
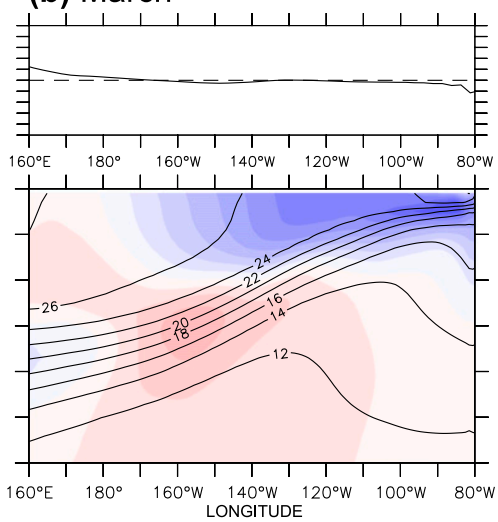

(e) September

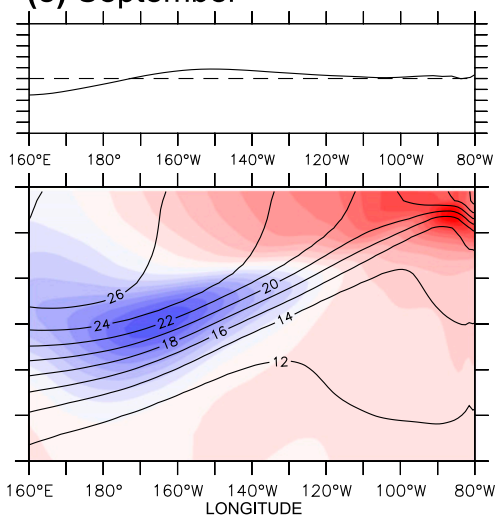

(c) May

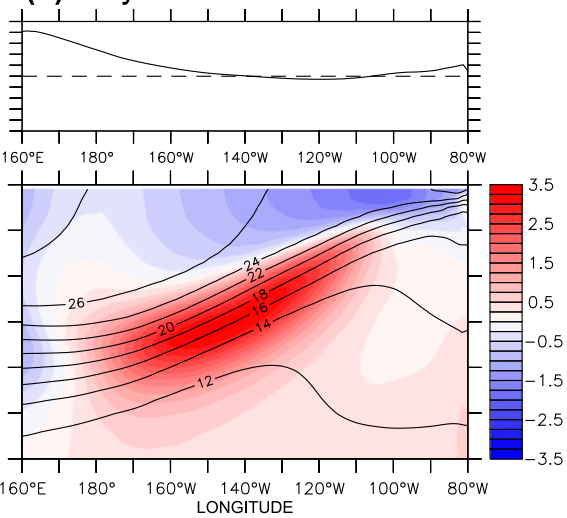

(f) November

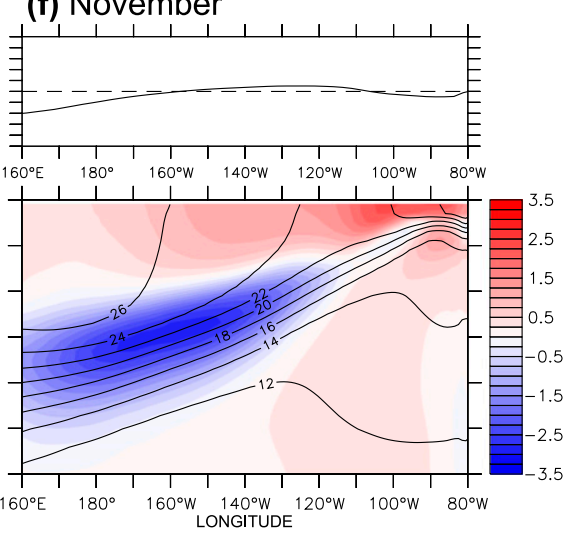

FIG. 11. Change in mean $5^{\circ} \mathrm{S}-5^{\circ} \mathrm{N} 10-\mathrm{m}$ zonal wind (top panels; $\mathrm{m} \mathrm{s}^{-1}$ ) and ocean temperature over the top $300 \mathrm{~m}$ (bottom panels; shaded, ${ }^{\circ} \mathrm{C}$ ) in the AE-preind experiment for (a) January, (b) March, (c) May, (d) July, (e) September, and (f) November. Contours show the isotherms of the preindustrial simulation for the same months, showing the depth of the thermocline.

simulations, Mantsis et al. (2013) finds that subtropical anticyclones respond to local heating anomalies as well as heating anomalies in monsoon regions. According to Rodwell and Hoskins (2001), differential heating of land and ocean in monsoon regions can strengthen winds on the western and equatorial sides of subtropical anticyclones. Specifically, winds over the equatorial Pacific in boreal summer respond to heating in the Asian monsoon region. In the AE-preind experiments, weakened subtropical anticyclones in May are associated with westerly wind anomalies in the western equatorial Pacific, while strengthened subtropical anticyclones in November are associated with easterly anomalies (Fig. 10). Detailed analysis of the effect of precession on subtropical anticyclones, such as the northwestward expansion of the $\mathrm{NH}$ Pacific summer anticyclone in response to increased summer insolation, can be found in Mantsis et al. (2013).

On a more local scale, there appears to be an enhancement of the anomalous wind in the western equatorial Pacific associated with shifts in convection. The present-day monsoonal circulation over the Maritime
Continent is characterized by a largely annual component of rainfall and a somewhat weaker semiannual component, with the annual cycle resulting primarily from the interaction of the seasonally reversing monsoonal winds with the terrain of the Maritime Continent (Chang et al. 2005). In the AE-preind experiment, changes in local insolation appear to affect this circulation pattern. In boreal spring, reduced insolation cools the Maritime Continent more than the western Pacific warm pool, shifting convection from the Maritime Continent toward the western Pacific and enhancing the westerly wind anomalies mentioned above. In November, convection is shifted from the South Pacific convergence zone toward Australia and the Maritime Continent. Temperature, precipitation, and wind anomalies are shown in Fig. 10, as well as the anomalous diabatic heating of the atmosphere, which is heavily influenced by changes in convection. Positive heating anomalies correspond relatively well with areas of wind speed convergence and precipitation.

Because the Coriolis parameter changes sign across the equator, anomalous westerly winds in May promote 
convergence of surface water and anomalous downwelling along the equator, deepening the thermocline and resulting in a positive temperature anomaly at depth (Fig. 11c). This warm anomaly propagates eastward along the thermocline as a wind-forced Kelvin wave and surfaces in the east in boreal summer, warming SSTs in the eastern equatorial Pacific before local insolation anomalies would do so (Figs. 11d,e). Anomalous easterly winds result in an analogous cold response that propagates along the thermocline during boreal autumn and winter (Figs. 11f,a,b).

When examined more closely, the response is somewhat more complex than the propagation of a free Kelvin wave because the forcing is not an isolated impulse function, as the wind anomalies change sign every six months. Thus there is likely to be a more complex picture in which the response to wind anomalies in the west is mixed with residual responses (perhaps involving off-equatorial Rossby waves) from earlier perturbations. Additionally, it is possible that the tropical Pacific response is affected by teleconnections from other regions, such as the tropical Atlantic [e.g., Rodríguez-Fonseca et al. (2009) for Atlantic Niño connections]. However, separating those potential teleconnections from the response to local forcings would be difficult in the current experiments, so those possibilities will not be explored.

In short, while SST changes in the western Pacific warm pool are driven more by the direct thermodynamic effect of insolation changes, SST changes in the eastern equatorial Pacific are primarily a response to wind anomalies in the western equatorial Pacific, which work to transmit temperature anomalies to the east as equatorial thermocline signals. The wind anomalies are associated with changes in the Pacific subtropical anticyclones as well as shifts in convection near the Maritime Continent. Insolation changes in the eastern Pacific reinforce this initial change, resulting in the large amplitude and asynchronous timing of eccentricity-driven SST anomalies in the eastern equatorial Pacific. Because the SM2.1 lacks oceanic advective heat transport, changes in SST in that model are primarily a direct thermodynamic response to insolation anomalies, resulting in more zonally uniform SST anomalies across the Pacific.

The above results are similar to those of Luan et al. (2012), but a more complete mechanism to explain the wind anomalies is presented here. The mechanism is also examined in Karamperidou et al. (2015), which describes a wind-forced annual Kelvin wave that affects the annual temperature cycle in the eastern equatorial Pacific. Karamperidou et al. (2015) also note that this response may have affected ENSO patterns in the midHolocene, especially in the eastern Pacific, by modifying the temperature stratification of the cold tongue. An and Choi (2014) examine mid-Holocene changes in equatorial
Pacific seasonality in the Paleoclimate Modelling Intercomparison Project phase 2 (PMIP2) and phase 3 (PMIP3) models and suggest that the decreased seasonality in the east is driven by insolation changes and increased cross-equatorial winds, which deepen the mixed layer, making SSTs less sensitive to surface heat flux changes. However, in the present research, the wind-forced thermocline signal from the west and insolation changes appear to be the dominant mechanisms of change.

\section{Effects of obliquity on equatorial Pacific seasonality}

Current hypotheses for the cause of the present-day equatorial Pacific seasonal cycle, mentioned in the introduction, suggest that much of the cycle ultimately stems from the seasonal changes in the tropical insolation gradient, which is affected by the obliquity of the earth. It is interesting, therefore, to see how much the seasonal temperature cycle might respond to the approximate $2.4^{\circ}$ shifts in obliquity that have occurred over the past $600 \mathrm{ka}$. To investigate this relationship, simulations with low and high obliquity are explored.

A change from high $\left(24.480^{\circ}\right)$ to low $\left(22.079^{\circ}\right)$ obliquity results in reduced summer insolation and slightly increased winter insolation in the midlatitudes of both hemispheres. The change in annual-mean insolation is $-13.2 \mathrm{~W} \mathrm{~m}^{-2}$ over the polar regions and $+3.2 \mathrm{~W} \mathrm{~m}^{-2}$ in the tropics. However, despite the weakened cross-equatorial seasonal insolation gradients, changes in equatorial Pacific seasonality are relatively small in both the CM2.1 and SM2.1 experiments, consisting of a few tenths of a degree warm anomaly near boreal winter and a cool anomaly during the remainder of the year in CM2.1. Compared to changes in equatorial Pacific seasonality driven by precession (Fig. 5a), the obliquity-driven anomalies (Fig. 5b) are relatively small, suggesting that changes in obliquity over the past $600 \mathrm{ka}$ have played little role in altering equatorial Pacific seasonality. Additional analysis of the Pacific SST response to obliquity can be found in Mantsis et al. (2011).

\section{Comparison with CMIP5 mid-Holocene results}

The idealized orbital experiments conducted with the GFDL CM2.1 and SM2.1 indicate that changes in the longitude of perihelion can produce large changes in equatorial Pacific seasonality and that tropical ocean dynamics are essential to producing such changes. To determine the extent to which this response may be model dependent, results from a mid-Holocene experiment with CM2.1 were compared with similar experiments conducted with the following 10 CMIP5 models: 
BCC_CSM1.1, CCSM4, CNRM-CM5, CSIRO Mk3.6.0, GISS-E2-R, HadGEM2-ES, IPSL-CM5A-LR, MIROCESM, MPI-ESM-P, and MRI-CGCM3. (Expansions of acronyms are available at http://www.ametsoc.org/ PubsAcronymList.) Mid-Holocene results from the CM2.1 and CMIP5 models were analyzed on the models' original (not fixed-angular) calendars as 100-yr monthly-mean climatologies. The mid-Holocene $(6 \mathrm{ka})$ is analyzed because it presents an approximate analog to $\mathrm{AE}$; ice sheets and atmospheric composition are the same or similar to $\mathrm{AE}$ and perihelion is very close to the autumnal equinox (the longitude of perihelion is $0.87^{\circ}$ versus $0^{\circ}$ at $\mathrm{AE}$ ), although 6-ka simulations have increased obliquity compared to the AE simulation $\left(24.1^{\circ}\right.$ versus $23.4^{\circ}$ ) and eccentricity is more similar to present day. All other forcings are identical between simulations. Equatorial insolation at $6 \mathrm{ka}$ (Fig. 1e) is similar to AE (Fig. 1a) but with a smaller annual component as a result of the reduced eccentricity.

In the GFDL CM2.1, the 6-ka minus preindustrial (6-ka-preind) experiment produces results qualitatively similar to the AE-preind experiment. SSTs in the eastern equatorial Pacific are up to about $1^{\circ} \mathrm{C}$ cooler from approximately January to June and up to about $1^{\circ} \mathrm{C}$ warmer during the rest of the year. SST changes in the western equatorial Pacific generally show a slight cooling. An analysis of the heat budget reveals that, like AE-preind, western Pacific changes are largely a direct thermodynamic response to insolation changes, while eastern equatorial Pacific SSTs respond to eastward-propagating thermocline signals reinforced by local insolation changes. Changes in winds near the Maritime Continent result in the thermocline signal propagation (Figs. 12a-f), similar to the AE-preind experiment.

SST changes in the 10-model CMIP5 ensemble are similar to those in CM2.1 though generally smaller in magnitude. Eastern equatorial Pacific SSTs are up to $1^{\circ} \mathrm{C}$ cooler from December to June and up to $0.5^{\circ} \mathrm{C}$ warmer from July to November. This results in a reduction of eastern equatorial Pacific seasonality, as observed in Masson-Delmotte et al. (2013) for most of the models in CMIP5 and PMIP2. Western Pacific SSTs show a slight cooling throughout the year. The CMIP5 ensemble's decrease in seasonality in the eastern equatorial Pacific is up to approximately $1.5^{\circ} \mathrm{C}$, compared to approximately $2^{\circ} \mathrm{C}$ in the CM2.1 experiment.

As in the CM2.1 experiment, the CMIP5 ensemble shows zonal wind variations in the western equatorial Pacific. Anomalous westerly winds in boreal spring create a warm thermocline signal that travels east along the thermocline (Figs. $12 \mathrm{~h}-\mathrm{j}$ ), while anomalous easterly winds in boreal autumn create a cold signal (Figs. 12k,l,g). These temperature anomalies, coupled with the thermodynamic effect of local insolation forcing, lead to the SST changes in the eastern equatorial Pacific. Among the individual models, there is some variation in this response, but all 10 models show a weakening of the seasonal cycle over much of the eastern equatorial Pacific and 9 of the models show anomalous westerly winds during boreal spring and anomalous easterly winds during boreal autumn in at least some of the western equatorial Pacific. The one model that does not match this pattern (MIROC-ESM) has anomalous easterly winds practically year-round in the western equatorial Pacific, though the wind anomalies are stronger in boreal autumn than in boreal spring. SST anomalies in this model are more zonally uniform than in many of the models, offering further evidence that wind-driven thermocline signals affect seasonality in the eastern Pacific.

This general agreement between CM2.1 and these 10 CMIP5 models suggests that the equatorial Pacific response to orbital forcing is not overly model dependent. Furthermore, it lends support to the hypothesis that precession affects equatorial Pacific seasonality not just through the direct thermodynamic effect of insolation anomalies, but by means of thermocline signals traveling at depth from the western Pacific.

\section{Conclusions and discussion}

The response of equatorial Pacific seasonality to astronomical forcing has been investigated using idealized simulations in which only orbital parameters are altered while all other forcings, such as ice sheet extent and atmospheric composition, are prescribed at preindustrial levels. From analysis of these simulations, the following conclusions can be drawn:

- Variations in the longitude of perihelion can result in large changes to the timing and magnitude of the equatorial Pacific seasonal temperature cycle in CM2.1. The eastern cold tongue region is most sensitive to this precession forcing and, according to a first harmonic fit, the Niño-3 region should have maximum seasonal SST range when the longitude of perihelion is around $155^{\circ}$ (i.e., perihelion in late February). SST changes in the western Pacific warm pool are comparatively smaller. SM2.1, a slab ocean model, exhibits smaller changes in eastern equatorial Pacific SSTs, suggesting that the CM2.1 response is strongly influenced by ocean dynamics.

- While precession-driven SST changes in the western equatorial Pacific are primarily a direct thermodynamic response to changes in insolation, changes in the eastern equatorial Pacific in CM2.1 initially result from 
(a) GFDL CM2.1, January

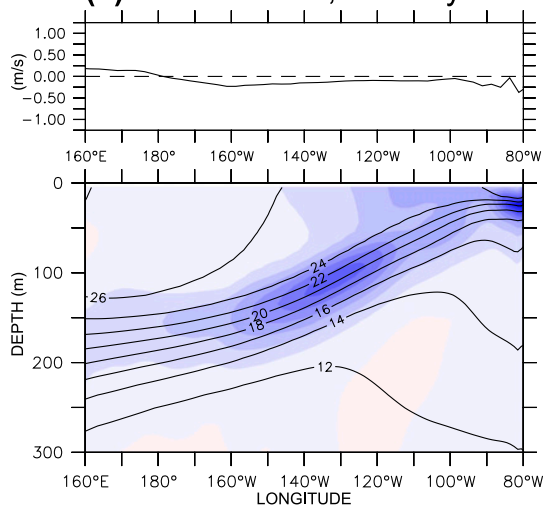

(d) July

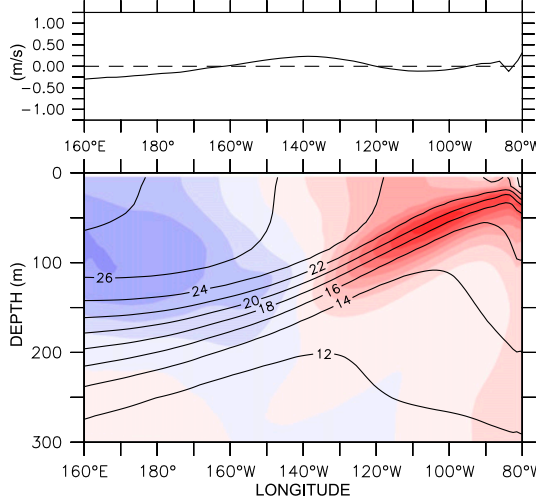

(g) CMIP5 ensemble, January

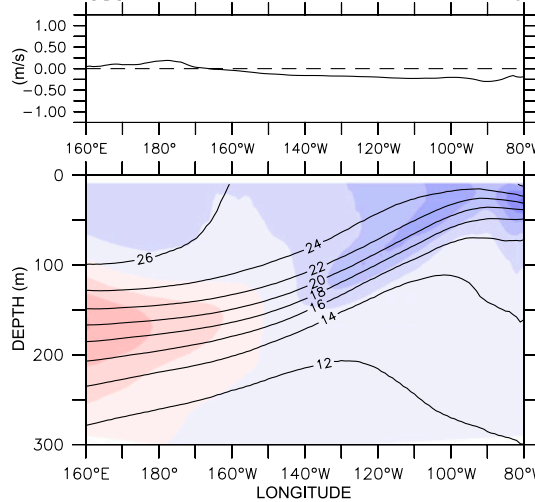

(j) July

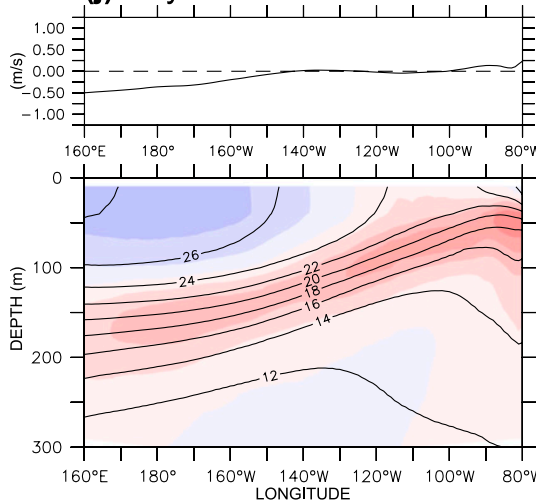

(b) March

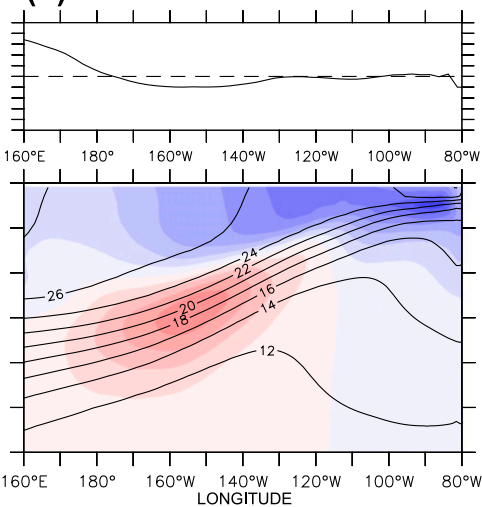

(e) September

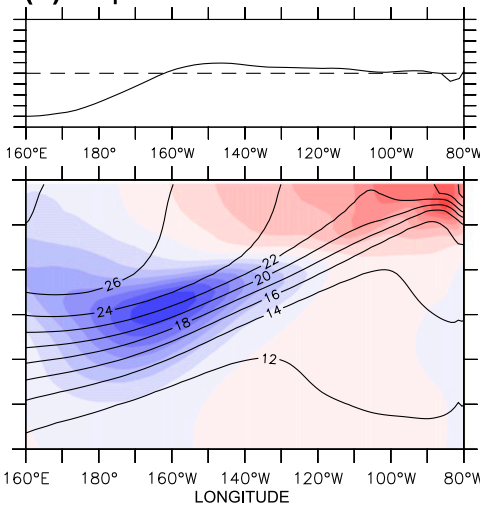

(h) March
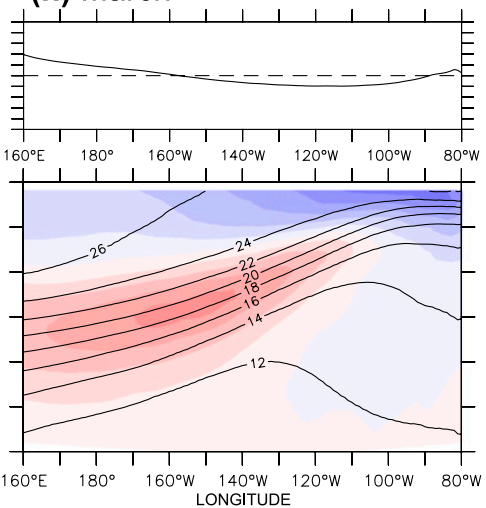

(k) September

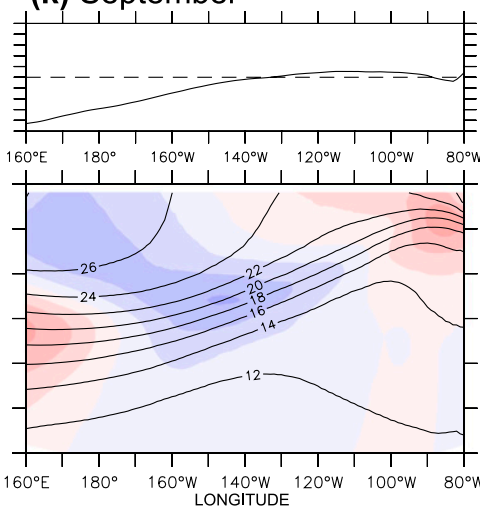

(c) May

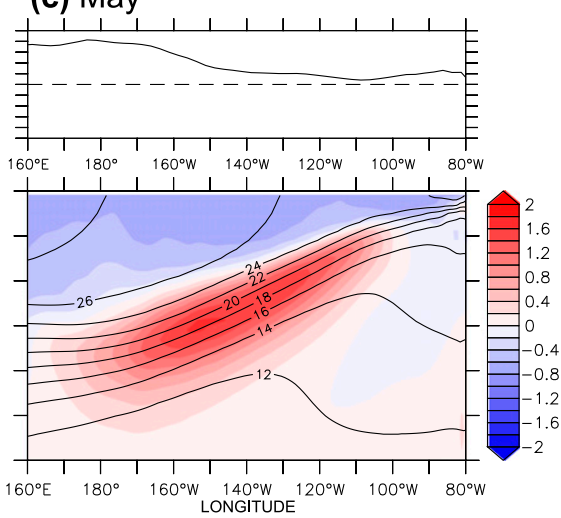

(f) November

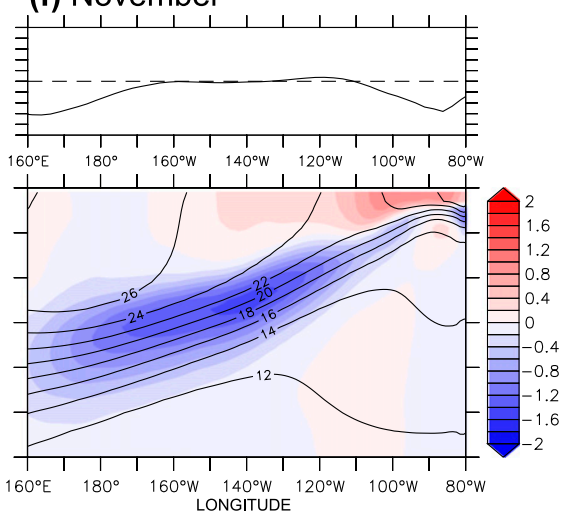

(i) May

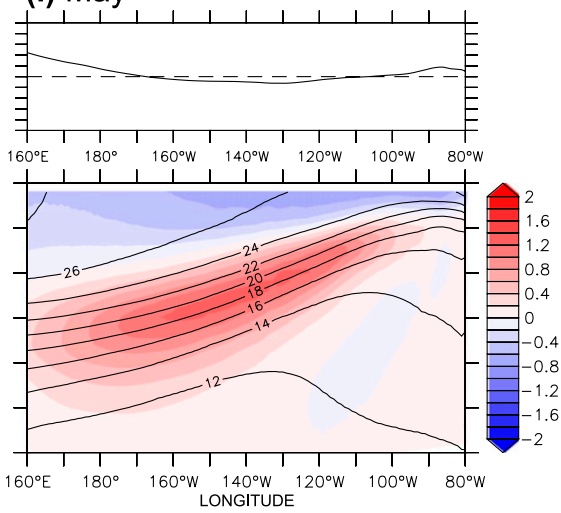

(I) November

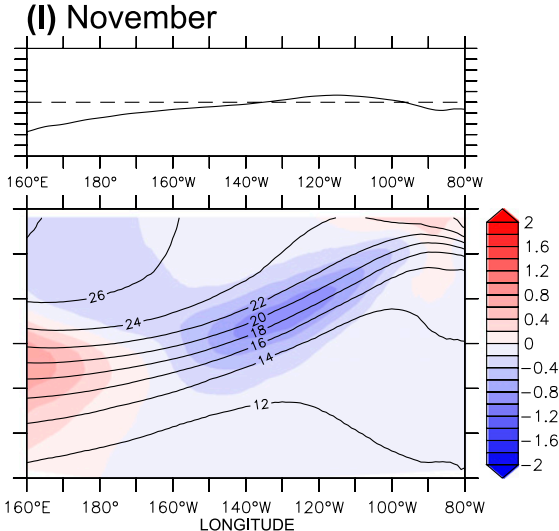

FIG. 12. As in Fig. 11, but for the 6-ka-preind experiments in (a)-(f) the GFDL CM2.1 and (g)-(l) the 10-model CMIP5 ensemble. 
thermocline signal propagation from the west. In boreal spring in the AE-preind experiment, a weakening of the Pacific subtropical anticyclones and an eastward shift of convection in the western equatorial Pacific are associated with anomalous westerly winds that promote convergence of surface water and downwelling. This results in a warm temperature anomaly that travels along the thermocline to the east, presumably mediated by equatorial Kelvin waves. A complementary cold thermocline response occurs during the other half of the year. These temperature anomalies surface in the east later in the year and, reinforced by local insolation changes, affect eastern equatorial Pacific seasonality.

- The seasonality of equatorial Pacific SSTs in CM2.1 is not very sensitive to changes in obliquity for the range of obliquity variations experienced during the past $600 \mathrm{ka}$.

- Mid-Holocene experiments using CM2.1 and 10 CMIP5 models show reductions in the eastern equatorial Pacific seasonal cycle, similar to the AE-preind experiment. Furthermore, many of the CMIP5 models replicate the changes in the western equatorial Pacific zonal winds and the thermocline signal mechanism that produces much of the temperature anomaly in CM2.1, indicating that this response is robust across the models considered.

- Because precession can produce significant changes in equatorial Pacific seasonality, it may be difficult to discern past ENSO variations from proxy records that reveal changes in extreme climate events but lack the temporal resolution necessary to distinguish seasonal from interannual variability.

Changes in equatorial Pacific seasonality due to orbital forcing may contribute to changes in climate in distant locations as a result of atmospheric teleconnections. The seasonal SST anomalies driven by precession can be comparable in magnitude to SST anomalies that accompany ENSO variability. Thus it is reasonable to assume that atmospheric circulation anomalies, including those affecting regions distant from the equatorial Pacific, may also be associated with changes in seasonality. Identifying such remote responses in the current experiments is challenging because the remote response to seasonal SST changes of the Pacific may be obscured by the direct response to local insolation changes at a given location. Experiments in which seasonal SST changes are prescribed in the equatorial Pacific but no direct forcing is applied to other climate regions would be ideal to isolate the effects of teleconnections.

Another implication of this work involves the interpretation of paleoclimate records from the eastern equatorial Pacific. A number of studies have used proxies of temperature or precipitation extremes to infer changes in ENSO variability (e.g., Moy et al. 2002; Koutavas et al. 2006; Koutavas and Joanides 2012; Conroy et al. 2008; McGregor et al. 2013b). However, because many such records do not have annual resolution, clearly distinguishing between variability on seasonal and interannual time scales is sometimes not possible. Therefore, caution should be employed when interpreting such records as being indicative of past changes in ENSO variability, as changes in seasonality may also be imprinted on them. For example, a record that shows a narrowed temperature range relative to today could be indicative of a reduction in ENSO variability, reduced amplitude of the seasonal cycle, or a combination of the two. Using annually resolved records would enable interannual variability to be isolated and thus alleviate any concerns about "mistaken identity." Coral records, such as those of Cobb et al. (2013) and McGregor et al. (2013a), can show changes at subannual resolution. However, coral records present difficulties of their own since they are often short enough that distinguishing forced changes from natural variability is difficult (Cobb et al. 2013).

Information about the sensitivity of SST seasonality to precession (Fig. 4) may be useful for identifying locations where records are less likely to be affected by orbitally forced changes in seasonality. Records developed from areas with large sensitivity to precession-forced seasonality changes, such as the eastern equatorial Pacific, are less ideal for studies of ENSO variation because of the potential for confusion between seasonal and interannual signals. Instead, areas where the influence of precession on seasonality is low but the standard deviation of interannual temperature change is high (see Fig. 14 in Wittenberg et al. 2006) may be better suited for studies of paleo-ENSO. While there is unfortunately some overlap of regions where both of these quantities are high, parts of the central Pacific, or even the eastern Pacific north of the equator, may be good regions for this purpose, barring other shortcomings of those locations. That said, it is unclear how much these results may be influenced by model biases such as the double ITCZ and overly strong cold tongue, so the exact regional anomalies shown in this paper should be viewed with appropriate skepticism when considering regions for further study.

Regarding model biases, double ITCZ and cold tongue biases are common to the current generation of climate models (Li and Xie 2014) and could influence results in several ways. For example, if model biases alter the location of western Pacific zonal wind anomalies, which drive the thermocline temperature anomalies, the timing of eastern Pacific SST anomalies could be affected. A downwelling region farther to the east would shorten the distance for a Kelvin wave to propagate, 
causing temperature anomalies to reach the eastern Pacific earlier in the year, provided Kelvin waves are the dominant mechanism of heat flux. A downwelling region farther to the west would have the opposite effect. Additionally, biases in the strength and location of the cold tongue could influence the extent of seasonal SST changes in the eastern Pacific. As future model improvements lead to reductions in these biases, it will be important to revisit the effects of orbital forcing on seasonality to determine to what extent, if any, results from the current generation of models have been affected by such biases.

Acknowledgments. The authors extend their thanks to F. Zeng, J. Krasting, and L. Sentman for their help in conducting these simulations, M. Khodri for running the mid-Holocene simulation, D. Pollard for help in making the calendar conversion, and the NOAA Geophysical Fluid Dynamics Laboratory at Princeton for use of their computing resources. We also thank two anonymous reviewers for their useful comments, which helped improve this paper. The National Science Foundation supported this research as part of their Paleo Perspectives on Climate Change program (Grant ATM0902735). Additional support was provided through a University of Texas Institute for Geophysics postdoctoral fellowship.

\section{REFERENCES}

An, S.-I., and J. Choi, 2014: Mid-Holocene tropical Pacific climate state, annual cycle, and ENSO in PMIP2 and PMIP3. Climate Dyn., 43, 957-970, doi:10.1007/s00382-013-1880-z.

Ashkenazy, Y., I. Eisenman, H. Gildor, and E. Tziperman, 2010: The effect of Milankovitch variations in insolation on equatorial seasonality. J. Climate, 23, 6133-6142, doi:10.1175/ 2010JCLI3700.1.

Berger, A., and M. F. Loutre, 1991: Insolation values for the climate of the last 10 million years. Quat. Sci. Rev., 10, 297-317, doi:10.1016/0277-3791(91)90033-Q.

Braconnot, P., Y. Luan, S. Brewer, and W. Zheng, 2012: Impact of Earth's orbit and freshwater fluxes on Holocene climate mean seasonal cycle and ENSO characteristics. Climate Dyn., $\mathbf{3 8}$, 1081-1092, doi:10.1007/s00382-011-1029-x.

Capotondi, A., A. Wittenberg, and S. Masina, 2006: Spatial and temporal structure of tropical Pacific interannual variability in 20th century coupled simulations. Ocean Modell., 15, 274-298, doi:10.1016/j.ocemod.2006.02.004.

Chang, C.-P., Z. Wang, J. McBride, and C.-H. Liu, 2005: Annual cycle of southeast Asia-Maritime Continent rainfall and the asymmetric monsoon transition. J. Climate, 18, 287-301, doi:10.1175/JCLI-3257.1.

Chang, P., 1994: A study of the seasonal cycle of sea surface temperature in the tropical Pacific Ocean using reduced gravity models. J. Geophys. Res., 99, 7725-7741, doi:10.1029/ 93JC03561.
_ 1996: The role of dynamic ocean-atmosphere interactions in the tropical seasonal cycle. J. Climate, 9, 2973-2985, doi:10.1175/1520-0442(1996)009<2973:TROTDO>2.0.CO;2.

Chen, G.-S., J. E. Kutzbach, R. Gallimore, and Z. Liu, 2011: Calendar effect on phase study in paleoclimate transient simulation with orbital forcing. Climate Dyn., 37, 1949-1960, doi:10.1007/s00382-010-0944-6.

Clement, A. C., R. Seager, and M. A. Cane, 1999: Orbital controls on the El Niño/Southern Oscillation and the tropical climate. Paleoceanography, 14, 441-456, doi:10.1029/1999PA900013.

Cobb, K. M., N. Westphal, H. R. Sayani, J. T. Watson, E. Di Lorenzo, H. Cheng, R. L. Edwards, and C. D. Charles, 2013: Highly variable El Niño-Southern Oscillation throughout the Holocene. Science, 339, 67-70, doi:10.1126/science.1228246.

Collins, M., and Coauthors, 2010: The impact of global warming on the tropical Pacific and El Niño. Nat. Geosci., 3, 391-397, doi:10.1038/ngeo868.

Conroy, J. L., J. T. Overpeck, J. E. Cole, T. M. Shanahan, and M. Steinitz-Kannan, 2008: Holocene changes in eastern tropical Pacific climate inferred from a Galápagos lake sediment record. Quat. Sci. Rev., 27, 1166-1180, doi:10.1016/ j.quascirev.2008.02.015.

Delworth, T. L., and Coauthors, 2006: GFDL's CM2 global coupled climate models. Part I: Formulation and simulation characteristics. J. Climate, 19, 643-674, doi:10.1175/JCLI3629.1.

Diaz, H. F., M. P. Hoerling, and J. K. Eischeid, 2001: ENSO variability, teleconnections and climate change. Int. J. Climatol., 21, 1845-1862, doi:10.1002/joc.631.

DiNezio, P. N., A. C. Clement, G. A. Vecchi, B. J. Soden, B. P. Kirtman, and S.-K. Lee, 2009: Climate response of the equatorial Pacific to global warming. J. Climate, 22, 4873-4892, doi:10.1175/2009JCLI2982.1.

Erb, M. P., A. J. Broccoli, and A. C. Clement, 2013: The contribution of radiative feedbacks to orbitally driven climate change. J. Climate, 26, 5897-5914, doi:10.1175/JCLI-D-12-00419.1.

- C. C. Jackson, and A. J. Broccoli, 2015: Using single-forcing GCM simulations to reconstruct and interpret Quaternary climate change, J. Climate, doi:10.1175/JCLI-D-15-0329.1, in press.

Guilyardi, E., A. Wittenberg, A. Fedorov, M. Collins, C. Wang, A. Capotondi, G. J. van Oldenborgh, and T. Stockdale, 2009: Understanding El Niño in ocean-atmosphere general circulation models. Bull. Amer. Meteor. Soc., 9, 325-340, doi:10.1175/2008BAMS2387.1.

Harrison, D. E., A. M. Chiodi, and G. A. Vecchi, 2009: Effects of surface forcing on the seasonal cycle of the eastern equatorial Pacific. J. Mar. Res., 67, 701-729, doi:10.1357/ 002224009792006179.

Hays, J. D., J. Imbrie, and N. J. Shackleton, 1976: Variations in the earth's orbit: Pacemaker of the ice ages. Science, 194, 11211132, doi:10.1126/science.194.4270.1121.

Jansen, E., and Coauthors, 2007: Palaeoclimate. Climate Change 2007: The Physical Science Basis, S. Solomon et al., Eds., Cambridge University Press, 433-497. [Available online at http://pubs.giss.nasa.gov/docs/2007/2007_Jansen_etal_1.pdf.]

Joseph, R., and S. Nigam, 2006: ENSO evolution and teleconnections in IPCC's twentieth-century climate simulations: Realistic representation? J. Climate, 19, 4360-4377, doi:10.1175/ JCLI3846.1.

Joussaume, S., and P. Braconnot, 1997: Sensitivity of paleoclimate simulation results to season definitions. J. Geophys. Res., 102, 1943-1956, doi:10.1029/96JD01989. 
Karamperidou, C., P. N. Di Nezio, A. Timmermann, F.-F. Jin, and K. M. Cobb, 2015: The response of ENSO flavors to midHolocene climate: Implications for proxy interpretation. $\mathrm{Pa}$ leoceanography, 30, 527-547, doi:10.1002/2014PA002742.

Knutti, R., D. Masson, and A. Gettelman, 2013: Climate model genealogy: Generation CMIP5 and how we got there. Geophys. Res. Lett., 40, 1194-1199, doi:10.1002/grl.50256.

Koutavas, A., and S. Joanides, 2012: El Niño-Southern Oscillation extrema in the Holocene and Last Glacial Maximum. Paleoceanography, 27, PA4208, doi:10.1029/2012PA002378.

, P. B. deMenocal, G. C. Olive, and J. Lynch-Stieglitz, 2006: Mid-Holocene El Niño-Southern Oscillation (ENSO) attenuation revealed by individual foraminifera in eastern tropical Pacific sediments. Geology, 34, 993-996, doi:10.1130/G22810A.1.

Kug, J.-S., J. Choi, S.-I. An, F.-F. Jin, and A. T. Wittenberg, 2010: Warm pool and cold tongue El Niño events as simulated by the GFDL CM2.1 coupled GCM. J. Climate, 23, 1226-1239, doi:10.1175/2009JCLI3293.1.

Lengaigne, M., and G. A. Vecchi, 2010: Contrasting the termination of moderate and extreme El Niño events in coupled general circulation models. Climate Dyn., 35, 299-313, doi:10.1007/s00382-009-0562-3.

Li, G., and S.-P. Xie, 2014: Tropical biases in CMIP5 multimodel ensemble: The excessive equatorial Pacific cold tongue and double ITCZ problems. J. Climate, 27, 1765-1780, doi:10.1175/ JCLI-D-13-00337.1.

Li, T., and G. H. Philander, 1996: On the annual cycle of the eastern equatorial Pacific. J. Climate, 9, 2986-2998, doi:10.1175/ 1520-0442(1996)009<2986:OTACOT>2.0.CO;2.

Lin, J.-L., 2007: The double-ITCZ problem in IPCC AR4 coupled GCMs: Ocean-atmosphere feedback analysis. J. Climate, 20, 4497-4525, doi:10.1175/JCLI4272.1.

Loulergue, L., and Coauthors, 2008: Orbital and millennial-scale features of atmospheric $\mathrm{CH}_{4}$ over the past 800,000 years. Nature, 453, 383-386, doi:10.1038/nature06950.

Luan, Y., P. Braconnot, Y. Yu, W. Zheng, and O. Marti, 2012: Early and mid-Holocene climate in the tropical Pacific: Seasonal cycle and interannual variability induced by insolation changes. Climate Past, 8, 1093-1108, doi:10.5194/ cp-8-1093-2012.

Mantsis, D. F., A. C. Clement, A. J. Broccoli, and M. P. Erb, 2011: Climate feedbacks in response to changes in obliquity. J. Climate, 24, 2830-2845, doi:10.1175/2010JCLI3986.1.

,-- , B. Kirtman, A. J. Broccoli, and M. P. Erb, 2013: Precessional cycles and their influence on the North Pacific and North Atlantic summer anticyclones. J. Climate, 26, 45964611, doi:10.1175/JCLI-D-12-00343.1.

—, B. R. Lintner, A. J. Broccoli, M. P. Erb, A. C. Clement, and H.-S. Park, 2014: The response of large-scale circulation to obliquity-induced changes in meridional heating gradients. J. Climate, 27, 5504-5516, doi:10.1175/JCLI-D-13-00526.1.

Masson-Delmotte, V., and Coauthors, 2013: Information from paleoclimate archives. Climate Change 2013: The Physical Science Basis, T. F. Stocker et al., Eds., Cambridge University Press, 383-464. [Available online at https://www.ipcc.ch/pdf/ assessment-report/ar5/wg1/WG1AR5_Chapter05_FINAL.pdf.]

McGregor, H. V., M. J. Fischer, M. K. Gagan, D. Fink, S. J. Phipps, H. Wong, and C. D. Woodroffe, 2013a: A weak El Niño/ Southern Oscillation with delayed seasonal growth around 4,300 years ago. Nat. Geosci., 6, 949-953, doi:10.1038/ ngeo1936.

McGregor, S., A. Timmermann, M. H. England, O. Elison Timm, and A. T. Wittenberg, 2013b: Inferred changes in El Niño-
Southern Oscillation variance over the past six centuries. Climate Past, 9, 2269-2284, doi:10.5194/cp-9-2269-2013.

Merryfield, W. J., 2006: Changes to ENSO under $\mathrm{CO}_{2}$ doubling in a multimodel ensemble. J. Climate, 19, 4009-4027, doi:10.1175/ JCLI3834.1.

Moy, C. M., G. O. Seltzer, D. T. Rodbell, and D. M. Anderson, 2002: Variability of El Niño/Southern Oscillation activity at millennial timescales during the Holocene epoch. Nature, 420, 162-165, doi:10.1038/nature01194.

Pollard, D., and D. B. Reusch, 2002: A calendar conversion method for monthly mean paleoclimate model output with orbital forcing. J. Geophys. Res., 107, 4615, doi:10.1029/2002JD002126.

Prell, W. L., and J. E. Kutzbach, 1987: Monsoon variability over the past 150,000 years. J. Geophys. Res., 92, 8411-8425, doi:10.1029/ JD092iD07p08411.

Reichler, T., and J. Kim, 2008: How well do coupled models simulate today's climate? Bull. Amer. Meteor. Soc., 89, 303-311, doi:10.1175/BAMS-89-3-303.

Rodríguez-Fonseca, B., I. Polo, J. García-Serrano, T. Losada, E. Mohino, C. R. Mechoso, and F. Kucharski, 2009: Are Atlantic Niños enhancing Pacific ENSO events in recent decades? Geophys. Res. Lett., 36, L20705, doi:10.1029/2009GL040048.

Rodwell, M. J., and B. J. Hoskins, 2001: Subtropical anticyclones and summer monsoons. J. Climate, 14, 3192-3211, doi:10.1175/ 1520-0442(2001)014<3192:SAASM $>2.0$. CO;2.

Smith, T. M., R. W. Reynolds, T. C. Peterson, and J. Lawrimore, 2008: Improvements to NOAA's historical merged landocean surface temperature analysis (1880-2006). J. Climate, 21, 2283-2296, doi:10.1175/2007JCLI2100.1.

Stouffer, R. J., and Coauthors, 2006: GFDL's CM2 global coupled climate models. Part IV: Idealized climate response. J. Climate, 19, 723-740, doi:10.1175/JCLI3632.1.

Timm, O., A. Timmerman, A. Abe-Ouchi, F. Saito, and T. Segawa, 2008: On the definition of seasons in paleoclimate simulations with orbital forcing. Paleoceanography, 23, PA2221, doi:10.1029/2007PA001461.

Timmermann, A., S. J. Lorenz, S.-I. An, A. Clement, and S.-P. Xie, 2007: The effect of orbital forcing on the mean climate and variability of the tropical Pacific. J. Climate, 20, 4147-4159, doi:10.1175/JCLI4240.1.

Tziperman, E., L. Stone, M. A. Cane, and H. Jarosh, 1994: El Niño chaos: Overlapping of resonances between the seasonal cycle and the Pacific ocean-atmosphere oscillator. Science, 264, 7274, doi:10.1126/science.264.5155.72.

_ S. E. Zebiak, and M. A. Cane, 1997: Mechanisms of seasonalENSO interaction. J. Atmos. Sci., 54, 61-71, doi:10.1175/ 1520-0469(1997)054<0061:MOSEI >2.0.CO;2.

van Oldenborgh, G. J., S. Y. Philip, and M. Collins, 2005: El Niño in a changing climate: A multi-model study. Ocean Sci., 1, 8195, doi:10.5194/os-1-81-2005.

Vecchi, G. A., 2006: The termination of the 1997-98 El Niño. Part II: Mechanisms of atmospheric change. J. Climate, 19, 2647-2664, doi:10.1175/JCLI3780.1.

_ , and A. T. Wittenberg, 2010: El Niño and our future climate: Where do we stand? Wiley Interdiscip. Rev.: Climate Change, 1, 260-270, doi:10.1002/wcc.33.

Wang, Y., and Coauthors, 2008: Millennial- and orbital-scale changes in the East Asian monsoon over the past 224,000 years. Nature, 451, 1090-1093, doi:10.1038/nature06692.

Wittenberg, A. T., A. Rosati, N.-C. Lau, and J. J. Ploshay, 2006: GFDL's CM2 global coupled climate models. Part III: Tropical Pacific climate and ENSO. J. Climate, 19, 698-722, doi:10.1175/JCLI3631.1. 